\title{
Design and Analysis of Subscale and Full-Scale Buckling-Critical Cylinders for Launch Vehicle Technology Development
}

\author{
Mark W. Hilburger ${ }^{1}$ and Andrew E. Lovejoy ${ }^{2}$ \\ NASA Langley Research Center, Hampton, VA 23681 \\ Robert P. Thornburgh ${ }^{3}$ \\ Army Research Laboratory, Hampton, VA 23681 \\ and \\ Charles Rankin ${ }^{4}$ \\ Rhombus Consultants Group, Inc., Palo Alto, CA 94303
}

\begin{abstract}
NASA's Shell Buckling Knockdown Factor (SBKF) project has the goal of developing new analysis-based shell buckling design factors (knockdown factors) and design and analysis technologies for launch vehicle structures. Preliminary design studies indicate that implementation of these new knockdown factors can enable significant reductions in mass and mass-growth in these vehicles. However, in order to validate any new analysis-based design data or methods, a series of carefully designed and executed structural tests are required at both the subscale and full-scale levels. This paper describes the design and analysis of three different orthogrid-stiffened metallic cylindrical-shell test articles. Two of the test articles are 8-ft-diameter, 6-ft-long test articles, and one test article is a 27.5 -ftdiameter, 20-ft-long Space Shuttle External Tank-derived test article.
\end{abstract}

\section{Nomenclature}

A $=$ amplitude of measurement-based imperfection shape

$A_{11}=$ membrane stiffness in axial direction

$A_{22}=$ membrane stiffness in circumferential direction

$b_{r} \quad=$ orthogrid ring spacing

$b_{s} \quad=$ orthogrid stringer spacing

$D_{11} \quad=$ bending stiffness in axial direction

$D_{22}=$ bending stiffness in circumferential direction

$E \quad=$ Young's modulus

$h=$ stiffener (stringer and ring) height

$H=$ total orthogrid height $(H=t+h)$

$I \quad=$ measurement-based imperfection shape

$L \quad=$ cylinder test article length

$n=$ number of panels welded together to form cylindrical test article

$N_{\text {panel }}^{X} \quad=$ panel buckling line load (load per unit length)

\footnotetext{
${ }^{1}$ Senior Research Engineer, Structural Mechanics and Concepts Branch, Senior Member AIAA.

${ }^{2}$ Research Aerospace Engineer, Structural Mechanics and Concepts Branch, Senior Member AIAA.

${ }^{3}$ Research Aerospace Engineer, Vehicle Technology Directorate, Senior Member AIAA.

${ }^{4}$ Senior Research Engineer, Associate Fellow AIAA.
} 


$\begin{array}{ll}N_{\text {stiff }}^{x} & =\text { stiffener buckling line load (load per unit length) } \\ N_{c r} & =\text { cylinder buckling line load } \\ P_{c r} & =\text { cylinder buckling load } \\ R & =\text { cylinder radius } \\ t & =\text { skin thickness } \\ t_{\text {eff }} & =\text { effective shell wall thickness } \\ t_{r} & =\text { orthogrid ring thickness } \\ t_{s} & =\text { orthogrid stringer thickness } \\ X & =\text { axial coordinate } \\ Y & =\text { circumferential coordinate } \\ \Delta_{c r} & =\text { critical buckling end shortening for cylinder test article } \\ \varepsilon_{c r} & =\text { critical buckling strain for cylinder test article } \\ v & =\text { Poisson's ratio }\end{array}$

\section{Introduction}

Buckling is an important and often critical consideration in the design of lightweight launch-vehicle structures; therefore, robust, validated design criteria for thin-walled shells are needed to achieve optimal designs of these structures. Unfortunately, the current design guidelines ${ }^{1-4}$ have not been updated since they were first published in the late 1960's and early 1970's, and may not be able to take full advantage of the modern materials, precision manufacturing processes, and new structural concepts needed to produce the next generation of affordable and efficient launch vehicles. To this end, a design technology development program at NASA, the Shell Buckling Knockdown Factor (SBKF) project, is currently working to revise the existing design factors and recommendations for buckling-critical shell structures. ${ }^{5}$ To support the development and validation of these new design factors, the SBKF project is conducting a series of shell buckling tests on large-scale, integrally-stiffened aluminum cylinders. Currently, SBKF is targeting specific structural configurations including isogrid-stiffened and orthogrid-stiffened cylinders for large-diameter heavy-lift launch vehicles. These large metallic cylinders are typically constructed by welding several curved panel sections together along longitudinal weld lands to form a complete circular cylinder (Fig. 1). The validation testing requires that the test article designs and data obtained from the tests are representative of these types of large-scale launch vehicle cylinder structures, and that certain behavioral characteristics and failure modes shall be isolated and studied. For example, these types of integrally-stiffened, welded structures can exhibit several different failure modes including global buckling, local skin-pocket buckling (i.e., buckling of the thin skin between stiffeners), weld land buckling (buckling of the unstiffened welded joint regions), and stiffener buckling and crippling.

One of the challenges in the test program is to design each test article to exhibit a specific failure mode or sequence of failure modes. However, imperfection sensitivity in these buckling-critical, thin-walled shells can result in significant variability in the buckling loads and failure modes from test to test. In addition, nonlinear interactions between the various failure modes can occur, but many of these interactions are currently not well understood for some of the advanced concepts and material systems being considered. This lack of knowledge can lead to the design of structural test articles that do not exhibit the desired test behavior. Thus, detailed sensitivity studies are conducted by using geometrically nonlinear finite-element analysis to identify the geometric imperfection sensitivity trends, and to identify possible failure mode interactions in each test article. Once the sensitivity of the structural response is well characterized, this information can be used to design a test article that exhibits sufficient separation between the failure mode being isolated in the test and all other failure modes. This sensitivity information is also used to help define necessary manufacturing and testing requirements such as the machining tolerances for flatness, parallelism, and perpendicularity of the ends of the test article.

The SBKF project uses subscale, 8-ft-diameter test articles in the majority of its testing, however, it needs to be verified that all critical design and response characteristics of these subscale test articles (e.g., imperfection sensitivity and failure modes) will scale to the corresponding full-scale flight hardware. Incorrect scaling assumptions may negatively impact the relevance of the test data for future designs. Thus, several buckling tests on full-scale 27.5-ft-diameter orthogrid-stiffened aluminum barrels are also planned to verify scale-up of the subscale test data.

The design and analysis of three different shell buckling test articles is presented in this paper to illustrate some of the challenges associated with the design and analysis process. First, the finite-element analysis approach is 
described and the typical design and analysis approach is presented. Then, two different 8-ft-diameter test article designs (designated TA01 and TA03) and their associated buckling behaviors are presented. Finally, the design and analysis of a 27.5-ft-diameter, 20-ft-long Space Shuttle External Tank-derived test article (designated ETTA1) is presented.

\section{Finite-Element Models and Analysis}

The STAGS (STructural Analysis of General Shells) nonlinear shell analysis code ${ }^{6}$ is used to predict the buckling behavior of the compression-loaded cylinders presented herein. STAGS is a finite-element code designed for the static and dynamic analysis of general shells, and that can include the effects of geometric and material nonlinearities in analyses. The code includes a suite of robust nonlinear static and transient dynamic solution capabilities. In particular, STAGS has modified and full Newton nonlinear solution algorithms, and accounts for large rotations in the shell by using a co-rotational algorithm at the element level. The Riks arc-length pathfollowing method can be used to continue a solution up to and past limit points in a nonlinear response. STAGS also has a transient dynamic analysis capability that can be used to predict unstable buckling and snap-through responses in shell structures. The transient analysis includes an implicit time integration scheme and Rayleigh's mass-stiffness proportional damping.

The cylinders presented herein were modeled using a combination of quadrilateral shell elements and beam elements from the STAGS element library. The shell element is a flat facet-type element based on Kirchoff-Love thin shell theory and the nonlinear Lagrangian strain tensor. The prebuckling, buckling and postbuckling responses of the cylinders were typically determined by using a combination of the Riks arc-length path-following method, described previously, to compute the cylinder's stable quasi-static response and the nonlinear transient analysis option to predict any unstable buckling responses. The transient analysis was initiated from an unstable equilibrium state close to the limit point by incrementing the end displacement of the cylinder by a small amount. An initial time step of $1.0 \mathrm{E}-8$ seconds was used in the transient analysis and is automatically adjusted by the program as a function of the solution behavior. The transient analysis was continued until the kinetic energy in the shell was dissipated to a negligible level, which indicates that the transient response has attenuated. Once the transient analysis had attenuated to a near-steady-state condition, a load relaxation option in the code was used to establish a static equilibrium state.

\section{Typical Cylinder Design and Analysis Approach}

The hierarchical approach used in the design and analysis of the test articles is described in this section. First, preliminary sizing of the test article is conducted using simplified global buckling analyses and closed-form solutions for predicting other failure modes, such as skin buckling and stiffener buckling and crippling. Next, a detailed finite-element analysis of the proposed design is conducted to verify that the test article will exhibit the desired buckling behavior and design margins, and to identify areas of the test-article design that need refinement. Finally, after the test article has been fabricated, a high-fidelity simulation of the as-built test article buckling response is conducted to provide a final verification of the test-article design and to determine test instrumentation requirements. Details of each of the three phases of the design are presented next.

\section{A. Preliminary Design and Analysis}

The orthogrid stiffener pattern and design variables are shown in Fig. 2, where $t$ is the skin thickness, $t_{s}$ is the stringer thickness, $t_{r}$ is the ring thickness, $h$ is the stiffener (stringer and ring) height, $H$ is the total orthogrid height, $b_{s}$ is the stringer spacing, and $b_{r}$ is the ring spacing. The cylinder analysis coordinate system is shown in Fig. 3. During the design process, a variety of shell-wall thicknesses and stiffener patterns are investigated and one is ultimately chosen that meets the specified design requirements and constraints. The design requirements typically include a desired buckling load, buckling mode, and imperfection-sensitivity characteristics. Separation or margin between different failure modes is used to isolate specific behaviors and is achieved by applying safety factors on the different failure-mode calculations during the design cycle. Additional constraints were imposed on the design to account for manufacturing limitations such as minimum machining thicknesses, machining tolerances, weld-land geometry, and geometric constraints on the stiffener geometry that are required for panel bump forming (the process of forming a flat stiffened sheet into a curved panel section).

The preliminary design of the orthogrid-stiffened test articles considered herein uses a linear bifurcation buckling analysis of an idealized, uniform (i.e., no welds or other discontinuities), geometrically perfect cylinder with smeared stiffener properties to predict the global buckling load of the cylinder subjected to an axial 
compression load. Local skin buckling (buckling of the skin between stiffeners) was predicted using the following equation that was derived for an infinitely long simply supported curved panel (see Ref. 7 for similar derivations)

$$
N_{\text {panel }}^{x}=\frac{E t^{3} \pi^{2}}{3\left(1-v^{2}\right) b_{s}^{2}}\left(1+\frac{3\left(1-v^{2}\right) b_{s}^{4}}{4 R^{2} t^{2} \pi^{4}}\right)
$$

and stiffener buckling was predicted by using an equation that was derived for an infinitely long plate that is simply supported on one side and free on the other ${ }^{7}$, and is given by

$$
N_{\text {stiff }}^{x}=\frac{E t_{s}^{3}}{2(1+v) h^{2}}
$$

where $N_{\text {panel }}^{x}$ and $N_{\text {stiff }}^{x}$ are the buckling load for the panel and stiffener, respectively, $R$ is the cylinder radius, $E$ is the Young's modulus, and $v$ is the Poisson's ratio. Once the acreage design is chosen (i.e., the stiffener pattern), the test article proceeds to the detailed design phase.

\section{B. Detailed Design and Analysis}

The main objective of the detailed design phase was to verify that the proposed test article design would achieve the desired test results. To this end, nonlinear analyses of the test-article design were conducted and include the effects of structural details such as the weld lands and thickness variations that are typically required in the transition region between the stiffened acreage and the weld land (Fig. 4). In addition, the imperfection-sensitivity characteristics of each test article are assessed by including two different geometric imperfection shapes in the model. First, a traditional eigenmode imperfection shape is assumed and the amplitude is varied from zero to approximately $1.0 t_{\text {eff, }}$, where $t_{\text {eff }}$ is the effective shell-wall thickness often used to characterize the thickness of a stiffened skin (e.g., Ref. 1) and is given by

$$
t_{\text {eff }}=\sqrt[4]{\frac{144 D_{11} D_{22}}{A_{11} A_{22}}}
$$

where $D_{11}$ and $D_{22}$ are the bending stiffnesses in the axial and circumferential directions, respectively, and $A_{11}$ and $A_{22}$ are the membrane stiffnesses in the axial and the circumferential directions, respectively.

Next, a second imperfection sensitivity study is conducted which assumes an imperfection shape that is based on geometry measurements of actual friction-stir-welded barrels. ${ }^{8}$ This measurement-based imperfection shape, $I(x, \theta)$, is given by

$$
I(x, \theta)=-A \sin \left(\frac{x \pi}{L}\right)\left[\frac{2}{3} \cos \left(\frac{n \pi \theta}{180}\right)+\frac{4}{15} \cos \left(\frac{2 n \pi \theta}{180}\right)+\frac{1}{15} \cos \left(\frac{3 n \pi \theta}{180}\right)\right]
$$

where $A$ is the imperfection amplitude, $L$ is the length of the test article, and $n$ is the number of panel sections that comprise the test article. This equation results in a periodic geometric imperfection distribution around the circumference of the cylinder, as shown in Figure 5, and is characterized by large-magnitude inward distortions near the weld lands and smaller magnitude variations in the acreage (note, the imperfection shape in Figure 5 is for a test article constructed from 3 curved panel sections, $n=3$, and assumes an amplitude $A$ of 1.0 in.). It is assumed that this imperfection shape represents a worst-expected or worst-case as-built geometric imperfection for this type of construction, and should provide a good estimate of the expected behavioral characteristics of the test article. If no design deficiencies are identified during the detailed design and analysis phase, i.e., if the response characteristics meet the test requirements, then the test-article design is approved for fabrication. 


\section{High-fidelity Buckling Simulation}

Once the test article is fabricated, a final pretest analysis is conducted to provide detailed data for test planning and provide a final verification of the test article. This analysis includes additional refinements in the model to produce a high-fidelity simulation of the buckling test. In particular, the as-built geometric imperfections are measured and are included in the model to accurately simulate the test article response. The measured imperfections are included in the model by using a user-written subroutine that reads the imperfection data file and adjust the positions of each node in the finite-element mesh. In addition, the test fixtures are included in the model to ensure that the test article-to-test fixture interactions are accurately predicted (e.g., the interface stiffnesses and the postbuckling load redistribution) and to replicate the kinematics of the test fixtures and loading mechanisms. The data from this high-fidelity simulation is used to substantiate and/or refine the test procedure and assess the adequacy of the instrumentation for the test.

\section{Test-Article Designs}

The design and analysis of three different test article designs are presented in this section. Two of the test articles are 8-ft-diameter, 6-ft-long cylinders that are herein referred to as TA01 and TA03. The third test article is a 27.5-ftdiameter, 20-ft-long Space Shuttle External Tank-derived test article that is herein referred to as ETTA1. All the test articles are constructed from integrally-machined orthogrid-stiffened aluminum alloy panels that are friction-stir welded together along longitudinal weld lands (seams) to form complete circular cylinders (see Fig.1). The three test articles were designed to exhibit different buckling behaviors, including global buckling, weld-land buckling (buckling of the longitudinal weld seam) and local skin buckling. The three designs and the predicted behaviors are presented next.

\section{A. TA01 - Checkout Specimen}

\section{Preliminary design and analysis}

TA01 was designed to meet two specific test requirements. First, test results were needed to validate the testarticle design and analysis approach, and to verify the performance of a new purpose-built test setup used for the test program. Second, the test-article construction and test data should be relevant for the design of modern orthogridstiffened metallic launch vehicle structures currently being considered by NASA. Thus, a lightly stiffened design was developed for TA01 acreage and is summarized in Table 1. The test article was designed to exhibit global buckling as the first failure mode, and included large margins for material yielding and skin and stiffener buckling in order to reduce the potential for failure mode coupling. The skin is relatively thick at $0.100 \mathrm{in}$. to prevent pocket buckling, and the stiffeners were chosen to be short with a small height-to-thickness ratio, $h / t_{s}$ of 3 , to prevent stiffener buckling and crippling. This resulted in a design with a large shell-radius-to-effective-skin-thickness ratio, $R / t_{\text {eff }}$ of 231, which is representative of a large lightly loaded launch vehicle cylinder section, such as those found in the Space Shuttle External Tank or the upper stage of a heavy-lift launch vehicle. The test article was designed to be constructed from three, 120-degree arc-length, orthogrid-stiffened curved panel segments that would be friction-stir welded together along three longitudinal weld lands to form a circular cylinder.

Table 1. Acreage Design for TA01.

\begin{tabular}{cc}
\hline Orthogrid Variable & Value \\
\hline$t$ (in.) & 0.100 \\
$H$ (in.) & 0.400 \\
$h$ (in.) & 0.300 \\
$b_{S}$ (in.) & 4.00 \\
$t_{S}$ (in.) & 0.100 \\
$b_{r}$ (in.) & 4.00 \\
$t_{r}$ (in.) & 0.100 \\
$R / t_{\text {eff }}$ & 230.9 \\
\hline
\end{tabular}

Preliminary bifurcation buckling analysis of an idealized TA01 design, with uniformly distributed smeared stiffener properties and no weld-land detail, indicates a global buckling load of 2,219 lb/in. (total load of $669.2 \mathrm{kips}$ ) 
with the buckling mode shown in Fig. 6. The predicted axial strain at buckling is $1,850 \mu \varepsilon$. Material yielding, skin buckling (Eq. (1)), and stiffener buckling (Eq. (2)) have predicted margins of 2.96, 0.21, and 20.7 above the global buckling load, respectively, and suggest that the acreage design should meet the test requirements.

\section{Detailed design and analysis}

Next, a detailed model of the TA01 design was developed that includes discrete stiffeners and weld land details. The stiffeners were modeled as beams but did not include the taper detail in the transition region that is shown in figure 4 . The weld lands are $0.25 \mathrm{in}$. thick and extend $1.25 \mathrm{in}$. on each side of the weld line and the skin thickness in the transition region is $0.175 \mathrm{in}$. The length of the transition region between the weld land and the acreage (distance between the weld lands and the adjacent stiffeners) is approximately 2 in.

Results from a linear buckling analysis of the detailed TA01 model indicate that buckling will occur along the axial weld lands at a load level of 2,166 lb/in. (652.0 kips total load), with the mode shape shown in Fig. 7. The average line load at buckling is $2.4 \%$ less than the corresponding load from the preliminary smeared stiffener model. However, the axial strain at buckling is approximately $8 \%$ lower than that predicted for the smeared acreage model, which indicates that a portion of the axial load is being redistributed from the acreage to the axially stiff weld lands.

The design requirements for TA01 specified that it exhibit global buckling, i.e., buckling throughout the entire test article, and local weld land buckling was not desirable. Thus, additional longitudinal stiffeners were positioned adjacent to the axial weld lands to increase the local bending stiffness and to help promote buckling in the acreage of the cylinder. A number of stiffener configurations were investigated, but only the final design is presented here. Details of the final design, shown in Fig. 8, included the following modifications to reduce the tendency for local weld land buckling: (1) the thickness of the two outermost axial stiffeners of each panel was increased from $0.1 \mathrm{in.}$ to 0.25 in., (2) an additional 0.25-in.-thick axial stiffener was placed equidistant between these two stiffeners, and (3) the thickness of the circumferential stiffeners was increased from $0.1 \mathrm{in}$. to $0.25 \mathrm{in}$. for the sections between the axial weld land and the innermost 0.25 -in.-thick axial stiffener. This reinforced design was modeled using the same detailed modeling approach discussed in Section III. The predicted linear buckling load was 2,406 lb/in. (724.2 kips total load), with a buckling strain of 1,833 $\mu \varepsilon$. The linear bifurcation buckling mode shape for the redesigned TA01 is shown in Fig. 9, and is characterized by a global distribution of buckles similar to that predicted from the preliminary smeared stiffened model shown in Fig. 6 and appears to exhibit the desired buckling response for this test article. In particular, the eigenmode shapes from both cylinder models have 15 full waves around the circumference and multiple half waves along the length. However, the buckles near the reinforced weld lands in the detailed model show slightly greater magnitude displacements as compared to the acreage due to the lower bending stiffness in that region.

Next, a nonlinear analysis of the reinforced TA01 design was conducted to verify the design modifications and assess the buckling behavior of the cylinder. The predicted load-end-shortening response curve for the geometrically perfect test article is shown in Fig. 10 along with selected prebuckling and postbuckling radial displacement contours. The blue and red colored contours correspond to inward and outward radial displacements, respectively. The nonlinear analysis predicts a limit load of 2,346 lb/in., and is $2.5 \%$ lower than the linear buckling load for this detailed model. The deformation shape at the limit load is characterized by five longitudinal half-waves along the length of the cylinder and 15 full waves around the circumference, and is similar to the linear bifurcation analysis mode shape shown in Fig. 9: however, the magnitude of the displacements are clearly larger at the weld land. These weld-land displacements cause buckling to initiate in the weld-land region and lead to the overall global buckling of the test article. The global buckling response is associated with a $63 \%$ reduction in axial load, and a postbuckling deformation pattern that includes large-magnitude inward displacements at each axial weld land and throughout the acreage as shown in Fig. 10.

The final step in the detailed design and analysis stage TA01 was to examine its imperfection-sensitivity characteristics to determine the potential range of variability in buckling test results and to ensure that global buckling would be the primary failure mode. This was achieved by conducting a series of nonlinear analyses using the detailed model described previously, and including two different types of geometric imperfection shapes. Specifically, the effects of an eigenmode imperfection and the effects of a worst-expected imperfection shape based on Eq. (4) are presented and compared.

The predicted load-end-shortening response curves for TA01 with an eigenmode imperfection (see Fig. 9) are shown in Fig. 11 for imperfection amplitudes of 0.05, 0.10, 0.15 and 0.20 in., corresponding to $0.25 t_{\text {eff, }} 0.5 t_{\text {eff }}$, $0.75 t_{\text {eff, }}, 1.0 t_{\text {eff, }}$, respectively, along with the results for the geometrically perfect case. The response is characterized by a monotonically increasing load-end-shortening response with limit points that range from 1,400 and 1,500 lb/in. for the four imperfection amplitudes considered, and correspond to a $35-40 \%$ reduction in the buckling load as 
compared to the geometrically perfect cylinder. Radial deformations, similar to those shown in Fig 7, form in the cylinders from the onset of loading and result in a significant reduction in the effective axial stiffness of the cylinders. Overall, these results indicate that this test article design is sensitive to initial geometric imperfections; however, the axial stiffness reduction associated with this imperfection shape is not typically observed in this type of shell structure. Thus, a more physically meaningful imperfection shape was investigated by using Eq. (4), which is based on measurements of similar friction-stir welded orthogrid-stiffened cylinders and is assumed to be a worstexpected as-built imperfection shape. The load versus end-shortening responses for four imperfection amplitudes ranging from $0.1 \mathrm{in}$. to $0.4 \mathrm{in}$, corresponding to $0.5 t_{\text {eff, }}$ to $2.0 t_{\text {eff }}$, respectively, are shown in Fig. 12 along with the results from the geometrically perfect cylinder. The limit loads for these imperfection amplitudes range from 2,284 $\mathrm{lb} / \mathrm{in}$. to $1,603 \mathrm{lb} / \mathrm{in}$., and correspond to reductions in the buckling load from $5 \%$ to $33 \%$, respectively. For all of these cases, the prebuckling load-end-shortening response curve was linear up to the limit load. A typical radial displacement pattern at the limit load for TA01 with a 0.2-in.-amplitude imperfection is shown in Fig. 13. It can be seen how this type of imperfection causes the weld land to deform inward during loading. Buckling initiates in the weld land regions and is followed immediately by the overall buckling of the cylinder, with post-buckling displacements similar to those shown in Fig. 10.

Based on these results, TA01 appears to meet all the specified test requirements, that is, it exhibits global buckling behavior, skin and stiffener buckling do not appear to influence the global buckling, and it possesses similar structural details as a full-scale launch vehicle structure.

\section{High-fidelity buckling simulation}

After TA01 was fabricated, the as-built geometry of its outer surface was measured and is shown in Fig. 14. The blue and red colored contours correspond to inward and outward imperfections (deviations from the perfect circular cylinder), respectively, and the vertical dashed lines identify the location of the three longitudinal weld lands. The measured imperfection exhibits a small amplitude $(<0.1$ in.) short-wave-length periodic variation around the circumference and slight variation along its length, and is somewhat similar to the imperfection shape that is approximated by Eq. (4).

High-fidelity buckling analyses were conducted for TA01 and included the as-measured geometry data in the detailed model described in Section III C. In addition, representations of the test fixtures and load lines were included in the finite-element model to ensure accurate modeling of the stiffness and kinematics of the integrated test set-up. A typical finite-element mesh for the test analysis is shown in Fig. 15a, and the actual test set-up is shown in Fig. 15b for reference. The test article is located at the mid-length of the test set-up and is "sandwiched" between the upper and lower load-introduction structures. Vertical load lines (orange colored beams in Fig. 15b) apply load to the test article by extending and contracting 8 independent hydraulic actuators positioned near the bottom of the load lines. These components that comprise the test set-up are represented in the finite-element model with a combination of shell and beam elements.

The predicted load-end-shortening response of TA01 with the as-built geometric imperfection is presented in Fig. 16. In addition, points $\mathbf{a}-\mathbf{d}$ are identified on the curve and correspond to displacement contours shown in Figs. $17 \mathrm{a}-17 \mathrm{~d}$. The results indicate a linear prebuckling response up to the limit point. Prebuckling deformations at $20 \%$ and $40 \%$ of the critical load are shown in Fig. 17a and 17b, respectively, and show the formation of several ellipse-shaped inward dimples in the cylinder wall. As the prebuckling loading is increased, one dimple near the mid-length of the cylinder grows in magnitude (see Fig. 17c) and initiates the global buckling of the cylinder. The predicted buckling load is $2,021.7 \mathrm{lb} / \mathrm{in}$. and corresponds to a $15 \%$ reduction in the buckling load as compared to the geometrically perfect cylinder. Upon buckling, the axial load is reduced by approximately $60 \%$ and is associated with a reduction in overall stiffness caused by the large-magnitude radial deformations in the shell wall shown in Fig. 17d. It is interesting to note that, while the global buckling of the imperfect shell was predicted to initiate in the acreage of the cylinder, it exhibits post-buckling deformations that are almost identical to the ones predicted for the geometrically perfect shell in which buckling initiated at the weld lands as shown in Fig 10. It should also be noted that the high-fidelity simulation is able to predict the sudden increase in the end-shortening that occurs during the buckling event, i.e., the horizontal component of movement from point $\mathbf{c}$ to $\mathbf{d}$ on the load-end-shortening curve in Fig. 16. This behavior is typical for buckling test of this type and is associated with a release of elastic energy in the test structure. 


\section{B. TA03 - Subscale Launch-Vehicle Tank}

\section{Preliminary design and analysis}

TA03 was intended to meet two specific design and test requirements. First, it was necessary to verify that fullscale launch vehicle structural designs could be scaled down to representative 8-ft-diameter test articles and exhibit similar response characteristics, such as buckling modes and imperfection sensitivity. Second, test results were needed to validate finite-element model predictions of a local weld-land buckling phenomena that was identified in the preliminary design of Ares- 1 tank structures. ${ }^{9}$ To this end, an optimized design for a full-scale 18 -ft-diameter orthogrid-stiffened tank-like structure was developed and then scaled down to an 8-ft-diameter test article configuration. The full-scale acreage design assumed an internal pressure load of 25 psi and uniform axial compression of approximately 6,800 lb/in. (4,621 kips total load). The internal pressure was assumed to provide axial load relief and hoop stabilization (the internal pressure results in hoop tension loads in the skin and increases the cylinders resistance to buckling) in the design. The design requirements also specified that local skin buckling, stiffener buckling and crippling, and material yielding shall not occur before global buckling. The resulting fullscale design is summarized in Table 2, as are the analysis predictions for the buckling load based on a uniform smeared stiffener model. Next, a $44.3 \%$ scaling is applied to the full-scale design to create an 8-ft-diameter test article. However, several manufacturing and test constraints made necessary some modifications to the scaled design. Specifically, the resulting scaled skin thickness would have been 0.055 in., which is thinner than the minimum manufacturing thickness of 0.060 in. Thus, the skin thickness was set at the minimum 0.060 in. This acreage design is referred to as the initial scaled design and is summarized in Table 2. In addition, the test of TA03 would not include the internal pressure loading that was included in the design of the full-scale cylinder. However, without the stabilizing internal pressure, the cylinder would exhibit skin buckling prior to global buckling. In order to provide relevant test data for the design of the corresponding full-scale cylinder (the primary requirement for TA03), it was determined that the local skin buckling response needed to be eliminated from the response. This was achieved by modifying the initial TA03 stiffener design to include a greater number of thinner stiffeners, which would reduce the size of the skin pockets and eliminate the local buckling but was expected to have little effect on the global buckling load and imperfection-sensitivity characteristics provided that the total cross-sectional area of the stiffeners remained the same. Thus, the modified design consisted of reducing axial and circumferential stiffener spacing as needed to prevent pocket buckling and adjusting the axial and circumferential stiffener thicknesses to keep the overall cross-sectional area constant. First, the circumferential stiffener spacing was reduced from 5.184 to 4.314 in., and circumferential stiffener thickness was reduced from 0.069 to 0.060 in. (manufacturing minimum). Next, Eq. (2) was used to calculate a minimum axial stiffener thickness of 0.065 in., that could be used and still maintain a positive margin on stiffener buckling. Equation (3) was then used to calculate the axial stiffener spacing needed to prevent pocket buckling, and resulted in a spacing of 1.813 in., which corresponds to a predicted skin stress of 2,690 lb/in. These modifications result in a design with a radius to effective shell wall thickness ratio $\left(R / t_{\text {eff }}\right)$ of 84 , which is almost identical to the original full-scale tank design. In addition, this design has an $11.6 \%$ increase in axial stiffener cross-sectional area relative to the initial design, but this was needed in order to retain positive margins for stiffener crippling and pocket buckling. Material yielding would occur at axial strain levels of approximately $5,300 \mu \varepsilon$, with a margin of approximately 0.5 over that of the global buckling load. 
Table 2. Comparison of the Geometry and Response of LH2 Aft Barrel and Scaled Specimen Designs. Orthogrid Variable Launch-Vehicle Tank Initial TA03 Design Modified TA03 Design

$\begin{array}{cc}R \text { (in.) } & 108 . \\ L \text { (in.) } & 173.83 \\ t \text { (in.) } & 0.125 \\ H \text { (in.) } & 1.630 \\ h \text { (in.) } & 1.50 \\ b_{S} \text { (in.) } & 7.931 \\ t_{S} \text { (in.) } & 0.255 \\ b_{r} \text { (in.) } & 11.6 \\ t_{r} \text { (in.) } & 0.155 \\ R / t_{e f f} & 84 .\end{array}$

48.0

48.0

173.83

69.125

69.125

0.125

0.060

0.060

1.630

0.723

0.723

7.931

0.663

0.663

0.255

3.517

1.813

11.691

0.113

0.065

0.155

5.184

4.314

84.0

0.069

0.060

86.6

84.1

(Smeared-Stiffener Model)

\begin{tabular}{cccc}
\hline$P_{c r}(\mathrm{lb} / \mathrm{in})$. & 6,846 & 3,217 & 3,296 \\
$\Delta_{c r}(\mathrm{in})$. & 0.6117 & 0.2436 & 0.2423 \\
$\varepsilon_{c r}\left(10^{-3}\right)$ & 3.519 & 3.524 & 3.505 \\
\hline
\end{tabular}

\section{Detailed design and analysis}

A detailed model that included the weld land detail and discrete stiffeners was developed to verify the buckling behavior of the proposed TA03 design, as was done for TA01 in the previous section. Test article TA03 was to be constructed from three 120-degree-arc-length curved-panel sections and friction-stir welded together along longitudinal weld lands similar to TA01. For TA03, the weld land is 0.20 in. thick and 1.25 in. wide, and the skin in the transition region is 0.10 in. thick and 1.53 in. wide. First, a linear bifurcation buckling analysis was conducted on the detailed model of TA03. The predicted bifurcation buckling mode shown in Fig. 18a indicates buckling along the axial weld lands rather than local buckling in the skin pockets, as desired. The predicted buckling load is 2,613 lb/in. and is $20.7 \%$ lower than the buckling load from the preliminary analysis of the uniform cylinder without the weld land detail. In addition, a local model of a single panel section (120-degree arc-section between weld lands) was constructed and analyzed to verify that the proposed stiffener design did not exhibit excessive stress levels in the stiffeners that could cause stiffener buckling or material yielding. This model used shell elements for the skin and all stiffeners, and assumed symmetric boundary conditions along the longitudinal weld lands. The predicted linear bifurcation buckling load was 2,416 lb/in, and the mode shape, shown in Fig. 18b, consists of buckling along the axial weld land similar to those shown in Fig. 18a. The buckling load predicted for the local model is $7.5 \%$ lower than the corresponding detailed global cylinder model, and is attributed to differences in the torsional stiffness of the axial stiffeners between the local and global models, and the fact that the local model has tapered ends for the circumferential stiffeners reducing the local bending stiffness near the axial weld lands. A nonlinear analysis was also performed on the local model, and the results indicate a maximum axial strain of 3,100 $\mu \varepsilon$, which is well below the yield strain of the material, occurs at the longitudinal stiffeners adjacent to the axial weld lands.

Next, a nonlinear analysis of the TA03 cylinder design was conducted to verify the design modifications and assess the buckling behavior of the cylinder. The corresponding load-end-shortening response is shown in Fig. 19 along with radial-displacement contour plots at selected load levels during the response. The blue and red colored contours correspond to inward and outward radial displacements, respectively, and the vertical black lines show the locations of the longitudinal weld lands in the cylinder. The results indicate that the cylinder exhibits a linear prebuckling load-end-shortening response up to the limit point and that radial deformations develop near the weld lands. The predicted limit load for TA03 is 2,435 lb/in., and is 6.8\% lower than the corresponding linear buckling load (2,613 lb/in.). Upon buckling, the axial load is reduced by $7 \%$ and large-magnitude ellipse-shaped inward buckles form along the weld lands in the cylinder. TA03 is then subjected to additional compression loading until a second buckling event is predicted to occur that corresponds to the buckling of the acreage between the weld lands.

The final step in the detailed design and analysis stage TA03 was to examine its imperfection sensitivity characteristics and determine the potential range of variability in buckling test results. This was achieved by 
conducting a series of nonlinear analysis using the detailed model described previously, and including two different types of geometric imperfection shapes (similar to what was done for TA01 presented previously). The predicted behavior for TA03 with an eigenmode imperfection was very similar to that predicted for TA01 and is not presented here. The predicted load-end-shortening response curves for TA03 with the worst-expected geometric imperfection shape given by Eq. (4) and with four different imperfection amplitudes are shown along with the results from a geometrically perfect cylinder in Fig. 20. For imperfection amplitudes that range from 0.1 in. to 0.3 in. $\left(0.18 t_{\text {eff }}\right.$ to $0.525 t_{e f f}$ ), the prebuckling response is linear up to the limit point (buckling load) and marked with a filled circle symbol. The predicted buckling loads range from 2,271 lb/in. to 1,801 lb/in. and correspond to a $13 \%$ to $31 \%$ reduction in the buckling load as compared to the geometrically perfect detailed model of 2,613 lb/in. The buckling response (not shown in the load-end-shortening curves for clarity) of these cylinders are characterized by the dynamic buckling of the weld lands similar to that shown in Fig 19 for the geometrically perfect cylinder. In contrast, the cylinder with an imperfection amplitude of 0.4 in. $\left(0.70 t_{e f f}\right)$ exhibited a benign weld land buckling response at 1,626 lb/in., marked by the $\mathbf{X}$ symbol on the load-end-shortening curve, and then continued to sustain additional load to 2,580 lb/in. The predicted radial-displacement contours at the limit load for TA03 with selected imperfection amplitudes are shown in Fig. 21. Overall, the results indicate that the buckling response of TA03 can be very sensitive to imperfections that are associated with local distortions near the weld lands.

\section{High-fidelity buckling simulation}

After TA03 was fabricated, the as-built geometry of its outer surface was measured and is shown in Fig. 22. The blue and red contours correspond to inward and outward radial imperfections (deviations) relative to a geometrically perfect best-fit circular cylinder, respectively, and the dashed vertical lines indicate the location of the three longitudinal weld lands in the cylinder. The measured imperfection appears to be somewhat similar to the imperfection in TA01; however, distortions do appear to be more localized near the weld lands and appears to be similar to the imperfection shape approximated by Eq. 4.

A high-fidelity buckling analysis was conducted for TA03 and included the as-measured geometry data in the detailed model. The predicted load-end-shortening response of TA03 is presented in Fig. 23 and indicates a linear prebuckling response up to the first buckling point of 2,043.5 lb/in., marked with a filled black circle. At this initial buckling point, one ellipse-shaped dimple is predicted to form in TA03 at the weld land at the $60^{\circ}$ circumferential location, shown in Fig. 24a. Test article TA03 is then subjected to additional axial compression load from point $\mathbf{a}$ to a maximum load of 2,446.2 lb/in. at point $\mathbf{b}$ on the load-shortening curve in Fig. 23 and exhibits progressive buckling of the other remaining weld lands, as shown in Fig. 24b. Once reaching this maximum load, TA03 exhibits a significant buckling response which is characterized by a $25 \%$ reduction in axial load from point $\mathbf{b}$ to point $\mathbf{c}$ on the load-shortening curve and the formation of additional buckles in the acreage of the cylinder, as shown in Fig. 24c.

\section{Space Shuttle External-Tank-derived Test Article \#1 - ETTA1}

\section{Preliminary design and analysis}

Full-scale 27.5-ft-diameter test articles, such as ETTA1, are intended to meet several SBKF test requirements. First, test data is needed to verify that the behavioral characteristics obtained from the analysis and testing of subscale 8-ft-diameter test articles are relevant in the design of full-size vehicle structures, that is, to verify that the subscale test articles exhibit similar buckling behavior and that the data can scale up to the full-scale vehicle structures. Second, geometric imperfection measurements of as-built full-scale hardware are needed to verify assumptions on imperfection shapes and amplitudes used to develop future analysis-based knockdown factors. Third, test results are needed to validate finite-element model predictions of complex buckling phenomena in launch vehicle-like compression-loaded cylinders. To this end, several 27.5-ft-diameter cylinder test articles were designed that are based on excess Space Shuttle External Tank (ET) hardware and test fixtures. These full-scale cylinders are constructed from eight integrally-machined orthogrid panels that are friction-stir-welded together to form a complete cylinder. Because the test articles were based on existing ET hardware, the test-article design options were somewhat limited. Several design options and loading conditions were investigated that included a variety of buckling behaviors; however, only the final design and predicted response of ETTA1 is discussed here.

The acreage design for ETTA1 is summarized in Table 3. The actual test-article acreage geometry differs slightly from the geometry reported here. In particular, the axial stiffeners are slightly thicker towards the ends of the panels and the skin thickness is slightly greater in the pockets adjacent to the weld lands. These and other local 
details were neglected in all preliminary buckling calculations that assume smeared-stiffener properties, but were included in the detailed model presented later. The exact dimensions are not disclosed herein.

The buckling load predicted from a linear buckling analysis for a cylinder with smeared stiffener properties is 1,375 kip, which corresponds to a running load of 1,322 lb/in. The resulting buckling mode shape is characterized by 8 axial half-waves and 19 circumferential full-waves. However, Eq. (2) predicts skin buckling to occur at approximately 440 kip (427 lb. in running load) and is likely to be the initial failure mode for this test article design. Material yielding is not predicted to occur prior to local buckling since the predicted yielding load is in excess of $6,640 \mathrm{lb} / \mathrm{in}$. which corresponds to a margin greater than 15.5. Similarly, the stiffener crippling load, predicted using Eq. (3), is 2,872 lb/in. and corresponds to a margin greater than 5.0.

Table 3. Acreage design used in ETTA1.

\begin{tabular}{cc}
\hline Orthogrid Variable & Value \\
\hline$t$ (in.) & 0.09 \\
$H$ (in.) & 1.05 \\
$h$ (in.) & 0.96 \\
$b_{S}$ (in.) & 10.8 \\
$t_{S}$ (in.) & 0.09 \\
$b_{r}$ (in.) & 15.32 \\
$t_{r}($ in.) & 0.10 \\
$R / t_{\text {eff }}$ & 326.4 \\
\hline
\end{tabular}

\section{Detailed design and analysis}

A linear buckling analysis using a detailed model of ETTA1, which includes the weld lands and discrete stiffeners, predicts a buckling load of $565.6 \mathrm{lb} / \mathrm{in}$. and corresponds to local skin buckling of the acreage as shown in Fig. 25. This local buckling load is $24 \%$ higher than that predicted from Eq. (2), and is attributed to the conservative simply supported boundary conditions used in the simplified equation.

Next, a nonlinear analysis of a geometrically perfect ETTA1 cylinder design was performed with the detailed model in order to predict the sequence of buckling events in the proposed test article. The resulting load versus endshortening plot is shown in Figure 26. The first limit load occurs at $575 \mathrm{lb} / \mathrm{in}$., marked with a filled black circle at point $\mathbf{a}$, and is associated with skin buckling as shown in Fig. 27a. The predicted displacement contours show the skin buckling in the acreage and a uniform inward displacement of the axial weld lands relative to the acreage. The local skin buckling is accompanied by a small drop in axial load of approximately $14.4 \mathrm{lb}$./in. Additional axial compression is applied to the cylinder from point $\mathbf{a}$ to limit point $\mathbf{b}$ at $740 \mathrm{lb} / \mathrm{in}$. Displacement contours that correspond to point $\mathbf{b}$ are shown in Fig. 27b and indicate a significant growth in the magnitude of the skin-buckling deformations. In addition, the deformations show a multiple-half-wavelength pattern forming along each axial weld land, with the inward radial displacements initiating the buckling of the weld lands. The weld-land buckling was accompanied by a $28 \%$ reduction in axial load as indicated by the load-end-shortening curve (Fig. 26). The postbuckling displacement pattern is characterized by a single large ellipse-shaped buckle at the center of each weld land and a broad outward bulge across the center of each panel as shown in Fig. 27c. The maximum post-buckled displacement is approximately $2.7 \mathrm{in.}$ inward and $0.7 \mathrm{in}$. outward.

\section{High-fidelity buckling simulation}

Nonlinear analyses were performed on the detailed model to assess the imperfection sensitivity of ETTA1 subjected to a uniform compression load, and included imperfection shapes defined by Eq. (4) as well as the asmeasured geometry of ETTA1 shown in Fig. 28. The blue and red colored contours in Fig. 28 correspond to inward and outward radial imperfections and the dashed vertical lines indicate the locations of the longitudinal weld lands. Predicted load versus end-shortening response curves for ETTA1 with an imperfections defined by Eq. (4) are shown in Fig. 29, and are indicated by the dashed lines for three different imperfection amplitudes ranging from 0.25 in. to 0.75 in., corresponding to $0.5 t_{\text {eff, }}$ to $1.5 t_{\text {eff, }}$, respectively. In addition, the results from a model with the asmeasured geometric imperfection is indicated with a dashed blue line in the figure. The first limit points for ETTA1 with the assumed imperfection amplitudes of $0.25 \mathrm{in}$. and $0.5 \mathrm{in.} \mathrm{both} \mathrm{occur} \mathrm{at} 575 \mathrm{lb} / \mathrm{in}$. and are associated with local skin buckling, similar to that exhibited by the geometrically perfect shell (see Fig. 27a). After local skin buckling, additional end-shortening is simulated in the cylinders until global buckling of the weld lands is predicted, 
which is accompanied by a marked reduction in axial load level. In contrast, for larger magnitude weld land imperfections, e.g., 0.75 in. and the as-measured geometric imperfection, ETTA1 exhibits large-magnitude inward displacement at each of the weld lands from the onset of loading, as shown in Fig. 30, and does not undergo any significant local skin pocket buckling. For the case of ETTA1, the imperfection shape approximated by Eq. (4) and the as-measured geometry are very similar in character, and therefore, produce similar behaviors for the same amplitude.

Unfortunately, the gradual weld land buckling behavior predicted for ETTA1 did not meet the full intent of the original test requirement to produce "test results ... to validate finite-element model predictions of complex buckling phenomena". It was originally envisioned, that an unstable buckling response should be included in the test results similar to what was predicted for the geometrically perfect ETTA1 cylinder shown in Figs. 26 and 27. Thus, several design modifications and additional loading conditions were investigated to try to obtain a cylinder response that included an unstable buckling event. First, the detailed model of the imperfect cylinder was modified to include Isection stiffeners on the weld lands to retard the onset of buckling in the weld lands and promote instability in the acreage. Two different I-section stiffeners were considered and were placed either on the inside or the outside of the test article. The predicted load-end-shortening response curves for these configurations are shown in Fig. 31 along with the considered stiffener cross-sectional geometries. The smaller stiffeners delayed the onset of buckling in the weld land but the overall character of the behavior remained unchanged. The externally stiffened weld land with the larger stiffener indicated some promise in providing the desired buckling behavior, however, concerns over local stresses and failures associated with stiffener attachment, unknown manufacturing risks, and impact of this design change on the relevance of the test data caused the removal of this option from consideration. Next, a 1 psi internal pressure load was included in the finite-element model of the as-built ETTA1 cylinder with the hope that the pressure would reduce the magnitude of the imperfection at the weld land and result in a behavior closer to those predicted for ETTA1 with the smaller amplitude imperfections as shown in Fig. 29 (e.g., $A=0.25$ in., and 0.5 in.). The predicted load-end-shortening response curve for the geometrically imperfect ETTA1 subjected to combined 1 psi internal pressure and uniform axial compression is shown in Fig. 32, and selected radial displacement contours are shown in Fig. 33. The 1 psi internal pressure is applied to the cylinder first and corresponds to point $\mathbf{a}$ on the load-shortening response curve in Fig. 32. The corresponding displacement response is shown in Fig. 33a and indicates outward radial deformations of the cylinder wall near the weld lands (red contours). The axial compression load is then applied, and the load-shortening curve is linear up to approximately $530 \mathrm{lb} / \mathrm{in}$. (point $\mathbf{b}$ in Fig. 32), at which point local skin buckling begins to occur in the acreage as shown in Fig. 33b. Simultaneously, the weld lands begin to deform slightly inward until the first limit point is reached at point $\mathbf{c}$ and the weld lands located at 292.5 degrees and 337.5 degrees buckle, as shown in Fig. 33c. Additional end-shortening is applied to ETTA1 from approximately 0.15 in. to 0.265 in. (point $\mathbf{c}$ to point $\mathbf{d}$ ), and is characterized by a progressive buckling of each of the six remaining weld lands as shown in Fig. 33d. The final predicted failure event is associated with buckling of the acreage as shown in Fig. 33e for point $\mathbf{e}$, and is accompanied by a $10 \%$ reduction in axial load. Based on these results, it was determined that adding the 1 psi internal pressure load provided the best option for obtaining the desired test results.

\section{Concluding Remarks}

Three different buckling-critical orthogrid-stiffened aluminum test article designs and their corresponding buckling behaviors are described in the present paper. The three different test article designs were developed to meet several different test requirements and included behaviors such as global buckling, local skin buckling and longitudinal weld-land buckling. The design process and rational was discussed, and selected finite-element analysis results were presented to illustrate the design verification process. In addition, some of the challenges associated with developing test articles for buckling-critical imperfection-sensitive structures were described and design solutions were provided. The first test article, TA01, was designed to exhibit global buckling and was used to validate the test-article design process and to serve as a checkout test article in a new purpose-built buckling test facility at NASA. The second test article, TA03, was a 44\%-scale design of an optimized launch-vehicle tank-like cylinder, and was used to verify that full-scale designs could be scaled down and still exhibit similar behavioral characteristics, thus ensuring relevance of the subscale analysis and test data in the design of future full-scale launch-vehicle structures. Finally, a full-scale 27.5.ft-diameter Space Shuttle External-Tank-derived test article, ETTA1, was presented, which illustrated how as-built test article geometry can have a significant influence on the predicted behavior, and emphasizes the importance of conducting relevant sensitivity studies during the test article design process. The test results for the three test articles presented here are summarized in Ref. 10. 


\section{Acknowledgments}

This work was conducted as part of the NASA Engineering and Safety Center (NESC) Shell Buckling Knockdown Factor Project, NESC Assessment \#:07-010-E.

\section{References}

${ }^{1}$ Anonymous, "Buckling of Thin-Walled Circular Cylinders," NASA Space Vehicle Design Criteria, NASA SP8007, September 1965 (Revised 1968).

${ }^{2}$ Anonymous, "Buckling of Thin-Walled Truncated Cones," NASA Space Vehicle Design Criteria, NASA SP-8019, September 1968.

${ }^{3}$ Anonymous, "Buckling of Thin-Walled Doubly Curved Shells," NASA Space Vehicle Design Criteria, NASA SP8032, August 1969.

${ }^{4}$ Anonymous, "Isogrid Design Handbook," NASA CR-124075, February 1973.

${ }^{5}$ Hilburger, M.W., "Developing the Next Generation Shell Buckling Design Factors and Technologies," $53^{\text {rd }}$

AIAA/ASME/ASCE/AHS/ASC Structures, Structural Dynamics, and Materials Conference, Honolulu, HI, Apr. 2326, 2012.

${ }^{6}$ Rankin, C. C., "STAGS Users Manual, Version 6.0," Rhombus Consultants Group, Inc., Ste. D201, 1121 San Antonio Rd., Palo Alto, CA 94303.

${ }^{7}$ Brush, D.O., and Almroth, B.O., "Buckling of Bars, Plates, and Shells, " McGraw-Hill, Inc, New York, 1975.

${ }^{8}$ Thornburgh, R. P., and Hilburger, M. W., "Design of Orthogrid Cylinder Test Articles for the Shell Buckling Knockdown Factor Assessment,” NASA/TM-2010-216866, November 2010.

${ }^{9}$ Thornburgh, R. P., and Hilburger, M. W., "Longitudinal Weld Land Buckling in Compression-Loaded Orthogrid Cylinders,” NASA/TM-2010-216876, December 2010.

${ }^{10}$ Hilburger, M.W., Haynie, W.T., Lovejoy, A.E., Roberts, M.G., Norris, J.P., Waters, W.A., and Herring, H.M., "Subscale and Full-Scale Testing of Buckling-Critical Launch Vehicle Shell Structures," $53^{\text {rd }}$

AIAA/ASME/ASCE/AHS/ASC Structures, Structural Dynamics, and Materials Conference, Honolulu, HI, Apr. 2326, 2012. 


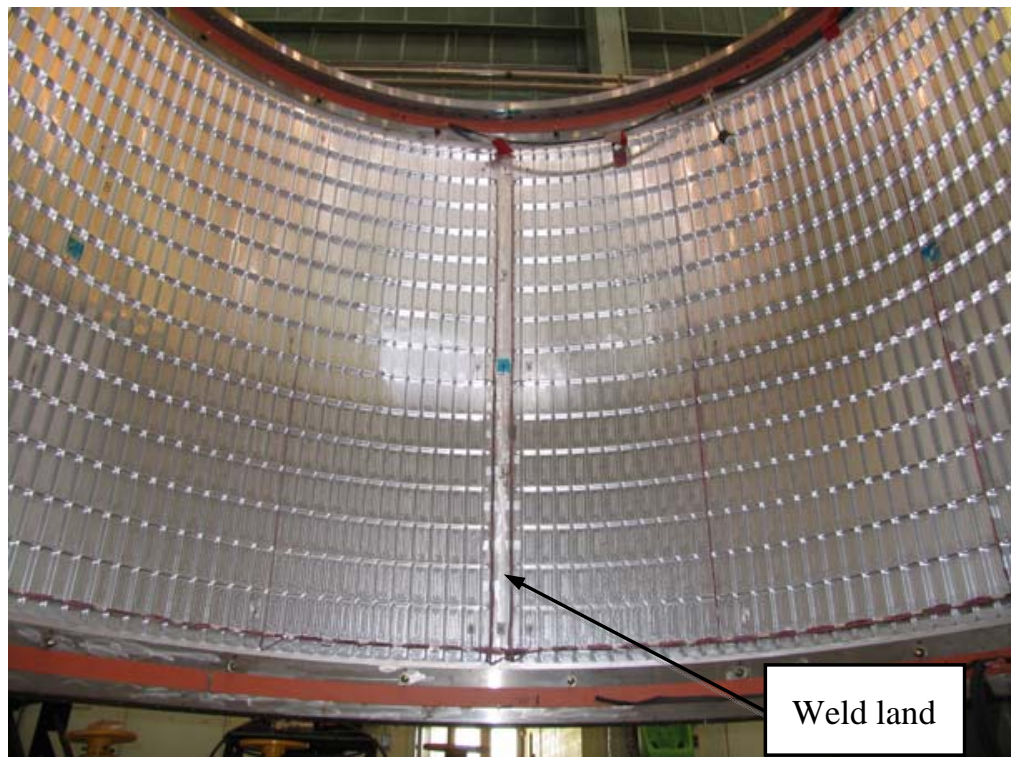

Figure 1. Internal view of an integrally-machined stiffener pattern of a typical aluminum orthogrid-stiffened test article, including a longitudinal weld land detail (vertical unstiffened weld land in the center of the image). 


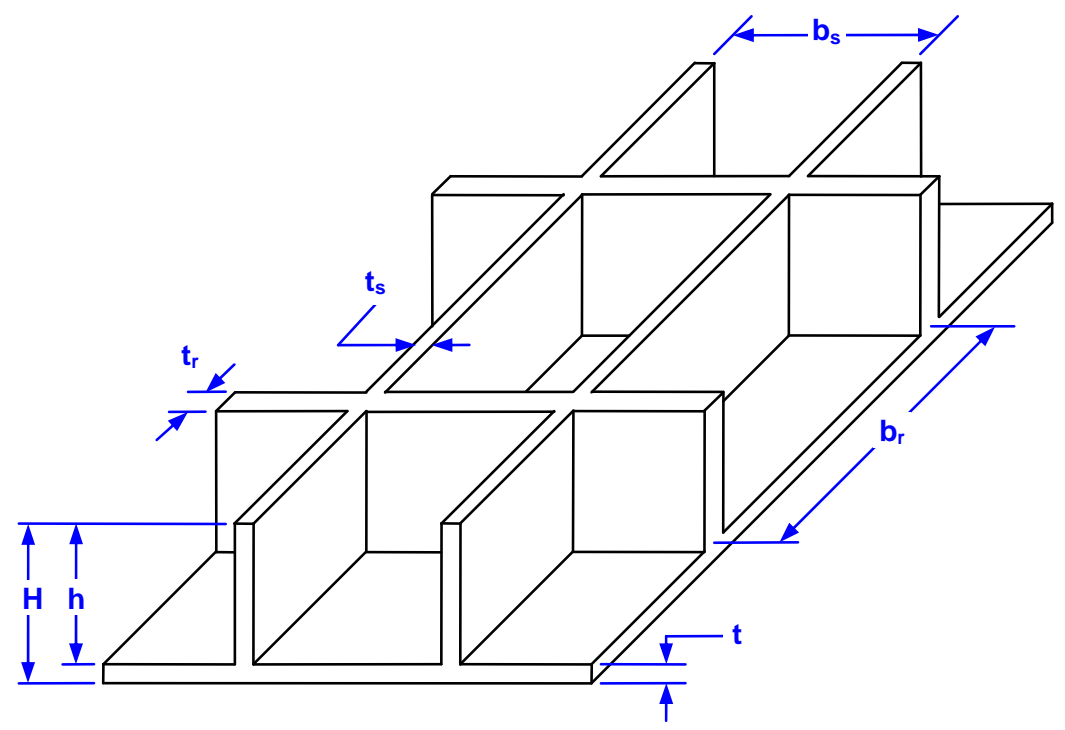

Figure 2. Orthogrid stiffener pattern and nomenclature. 


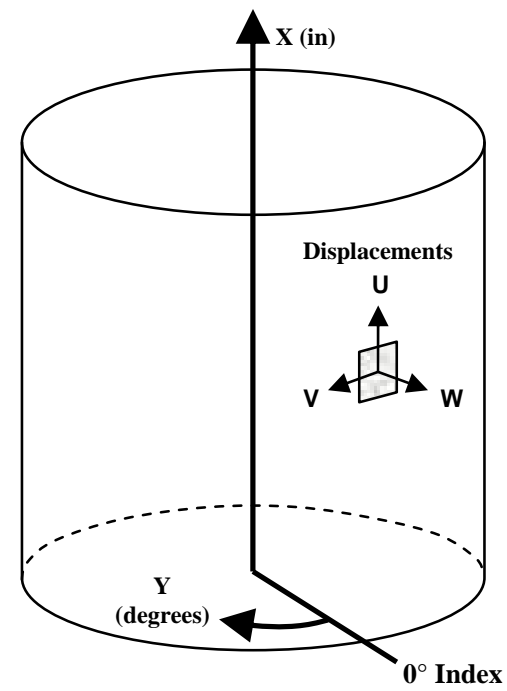

Figure 3. Cylinder analysis coordinate system used to display measured geometric imperfection data and predicted displacement contours. 


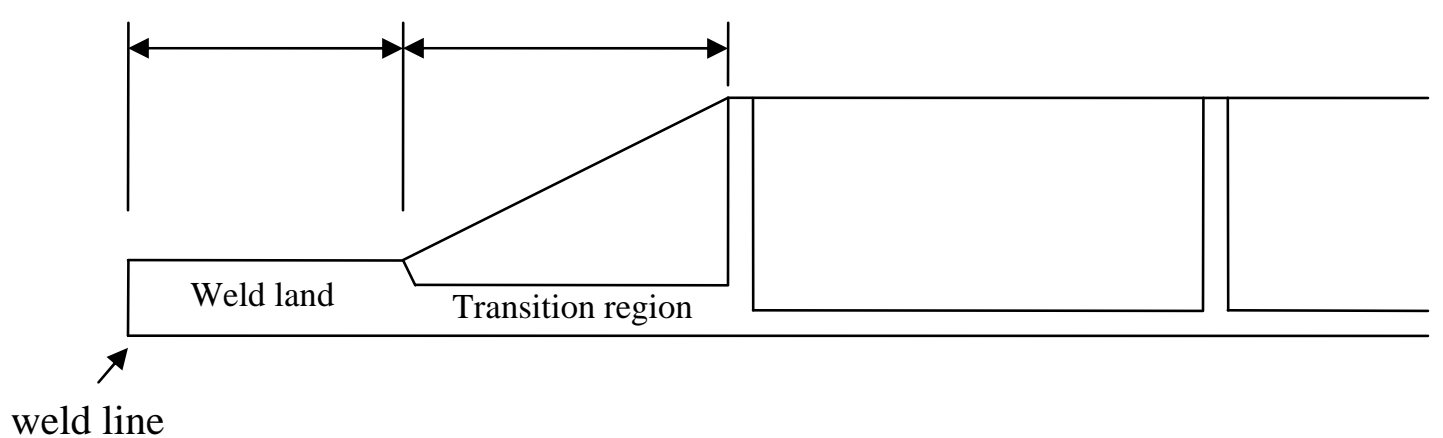

Figure 4. Cross-section view of a typical weld land design. 


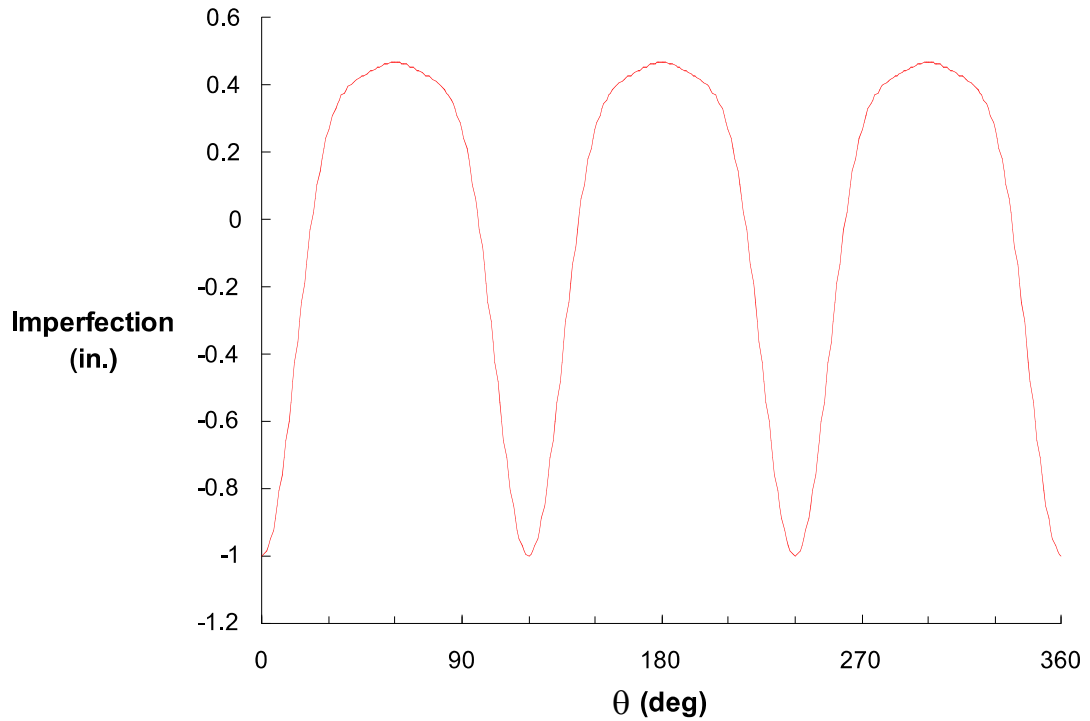

Figure 5. Worst-expected circumferential imperfection shape for a three panel cylinder, assuming an amplitude $A=1.0$ in. 


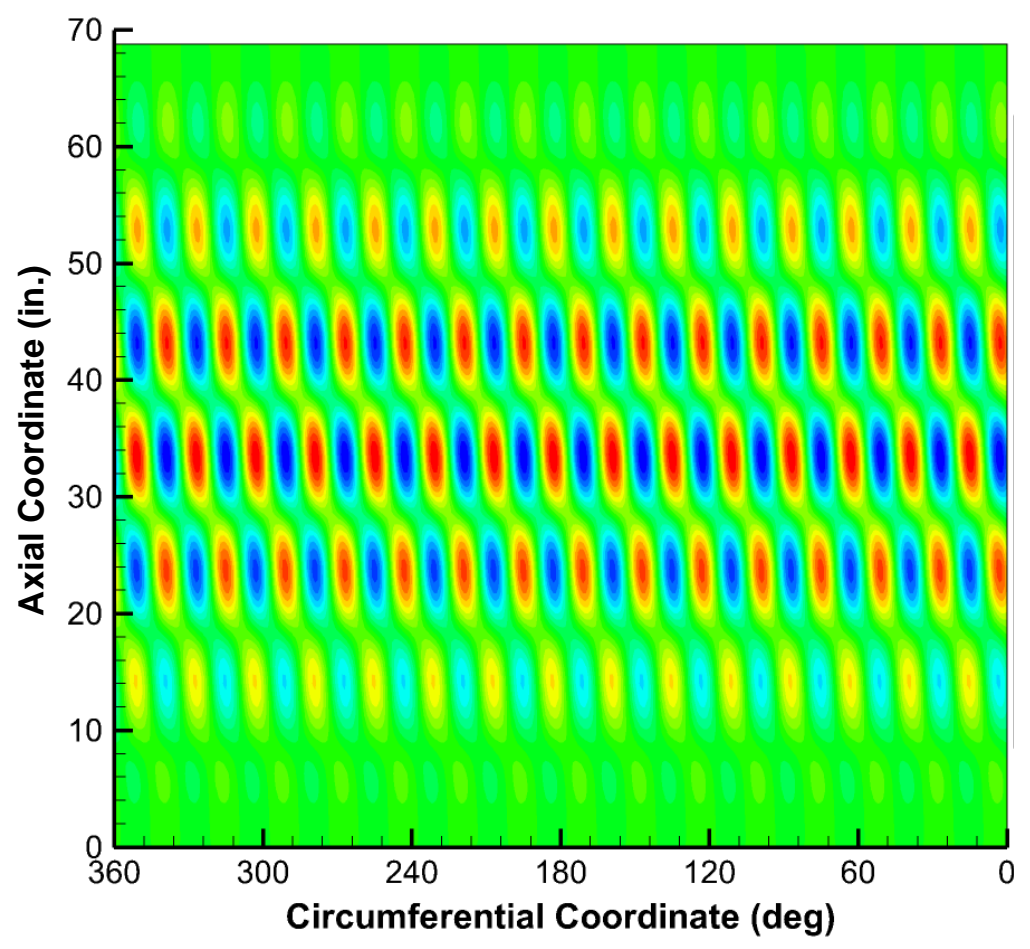

Figure 6. Linear buckling mode shape for TA01 with smeared stiffener properties. 


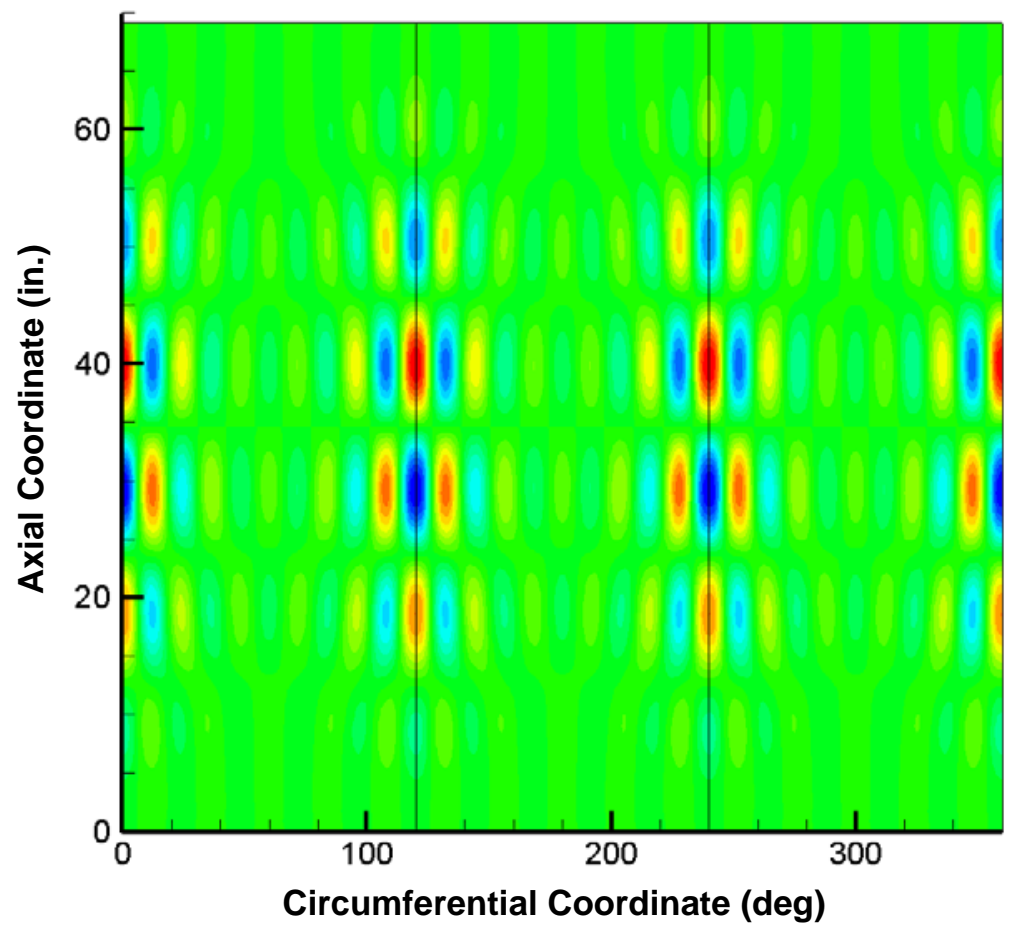

Figure 7. Linear buckling mode shape for a detailed model of TA01 with unreinforced weld lands. 


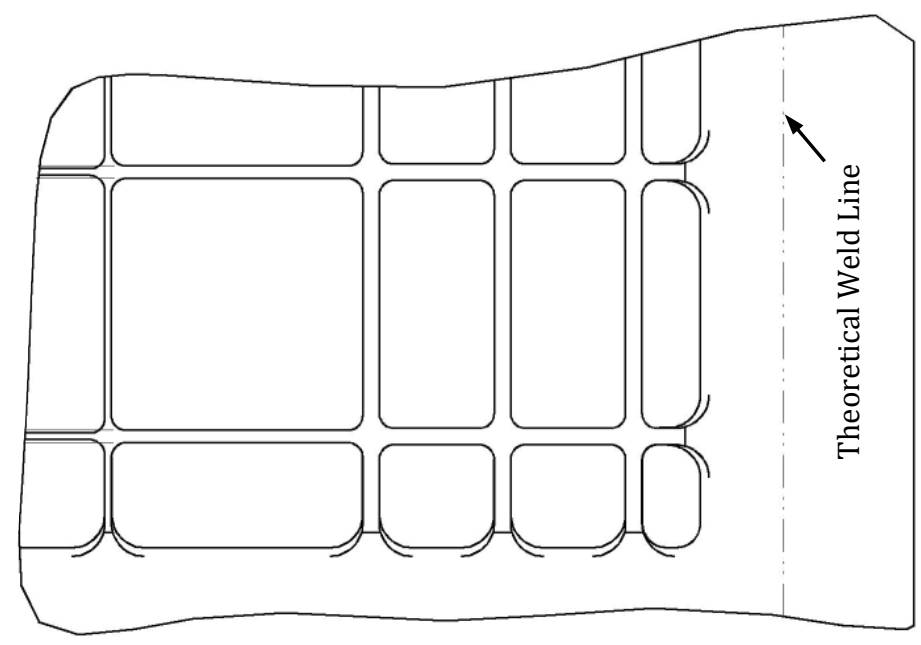

Figure 8. Modified stiffener geometry near the longitudinal weld lands in TA01. 


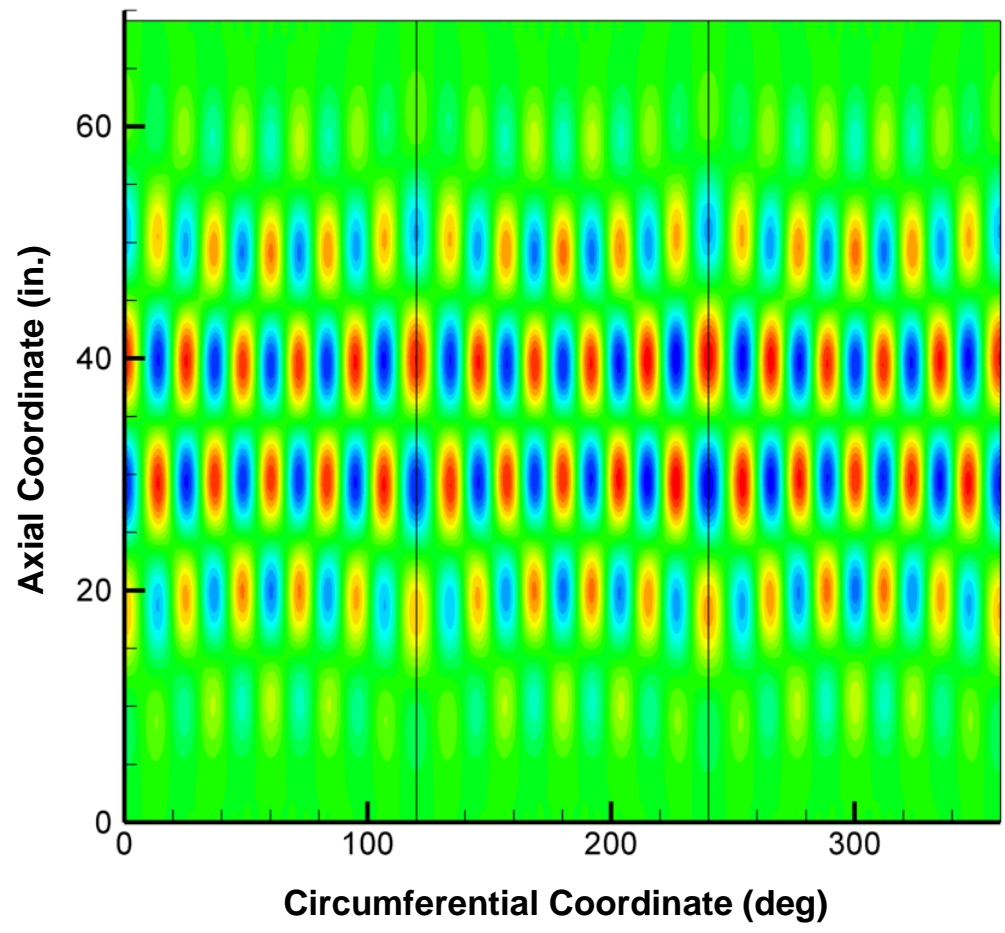

Figure 9. Linear buckling mode shape from a detailed model of TA01 with reinforced weld lands. 


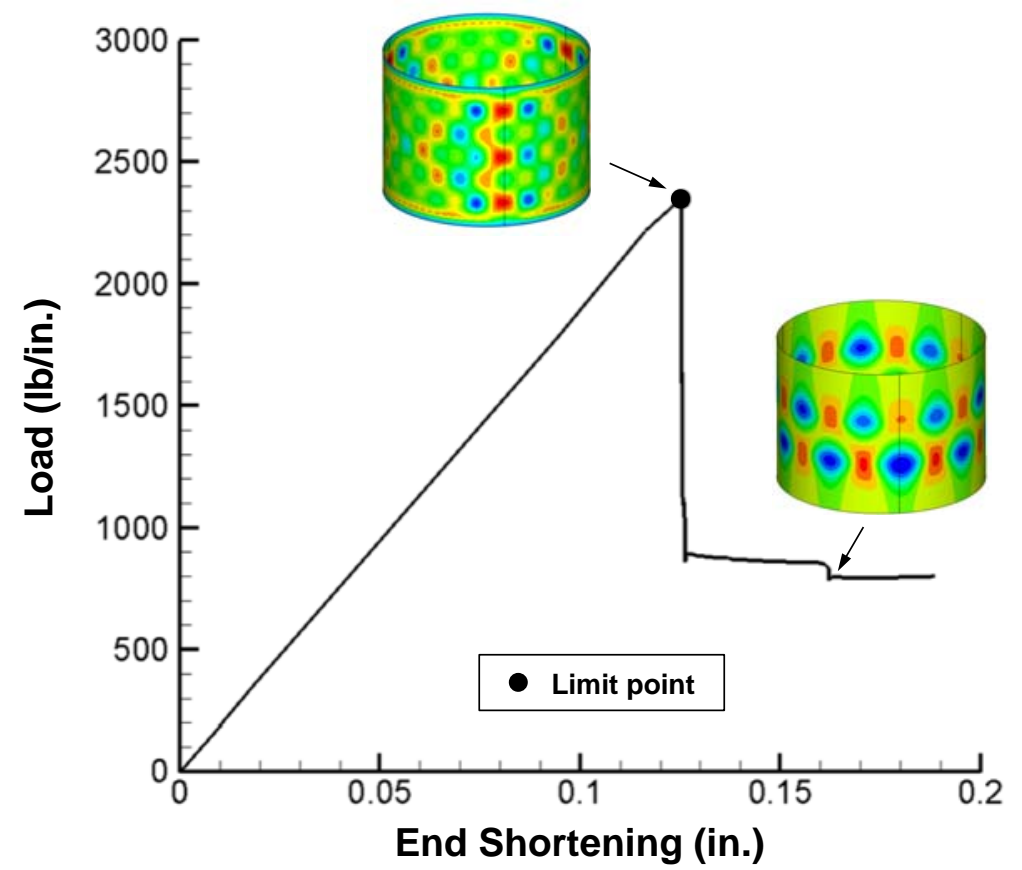

Figure 10. Predicted load-end-shortening response and selected radial displacement contours of geometrically perfect TA01 (red and blue contours correspond to outward and inwrad radial displacements, respectively). 


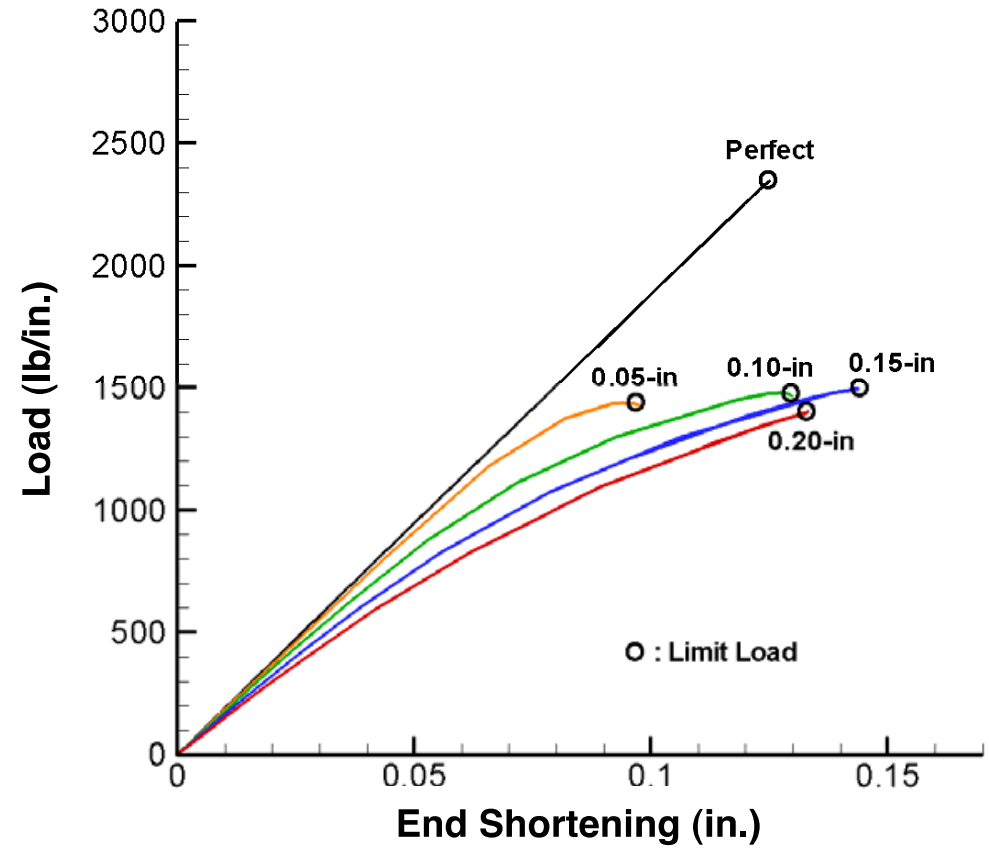

Figure.11 Predicted load-end-shortening response of TA01 for selected eigenmode imperfection amplitudes. 


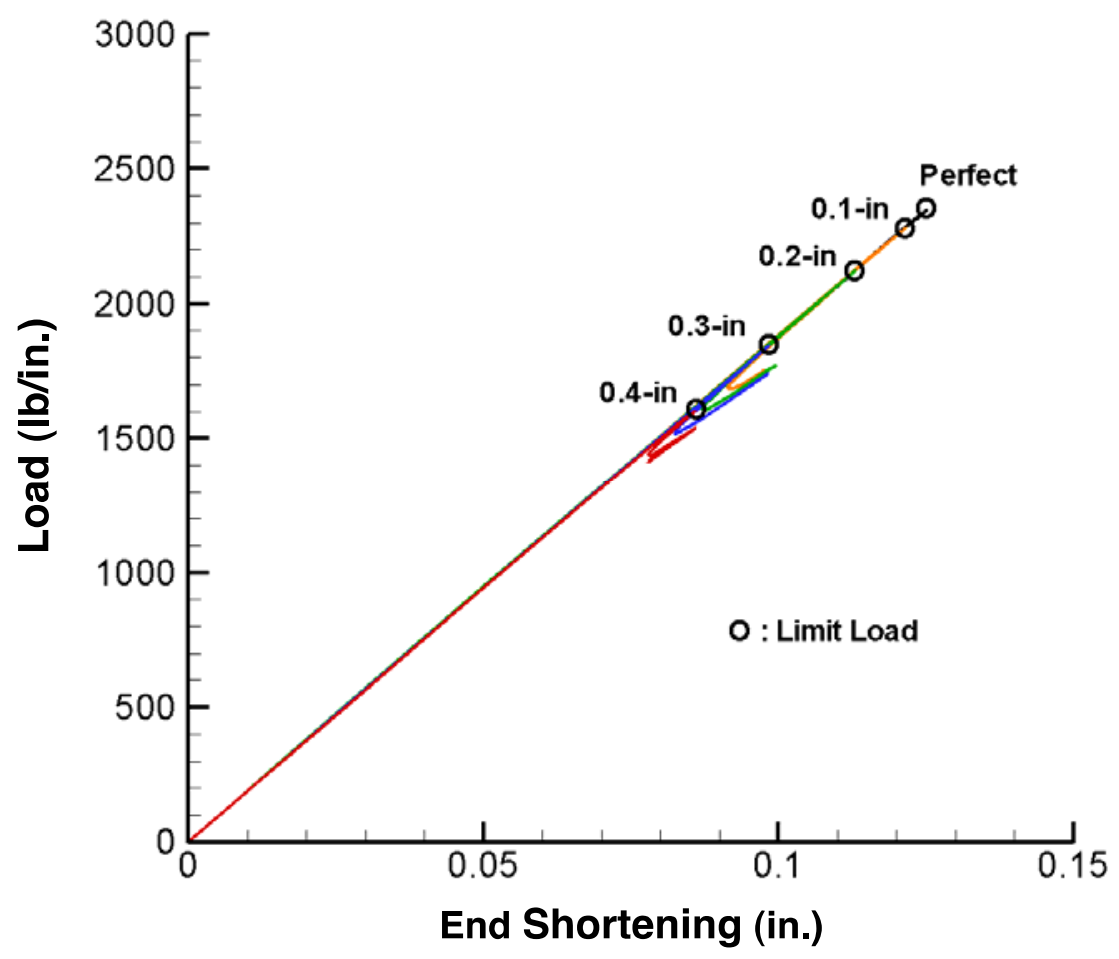

Figure.12 Predicted load-end-shortening response of TA01 for selected weld land imperfection amplitudes. 


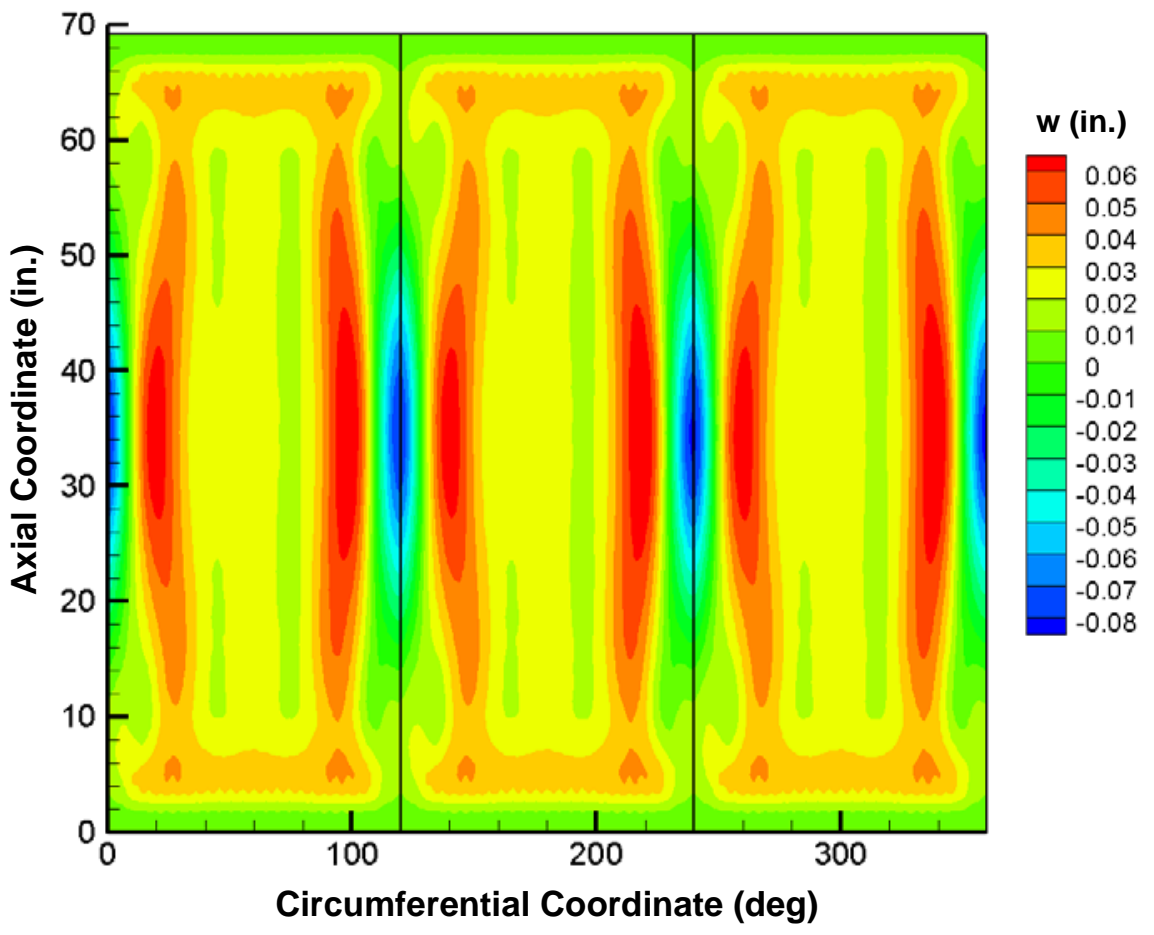

Figure.13 Predicted radial displacements for TA01 with an 0.2-in.-magnitude weld land imperfection at the limit load, 2,124 lb/in. 


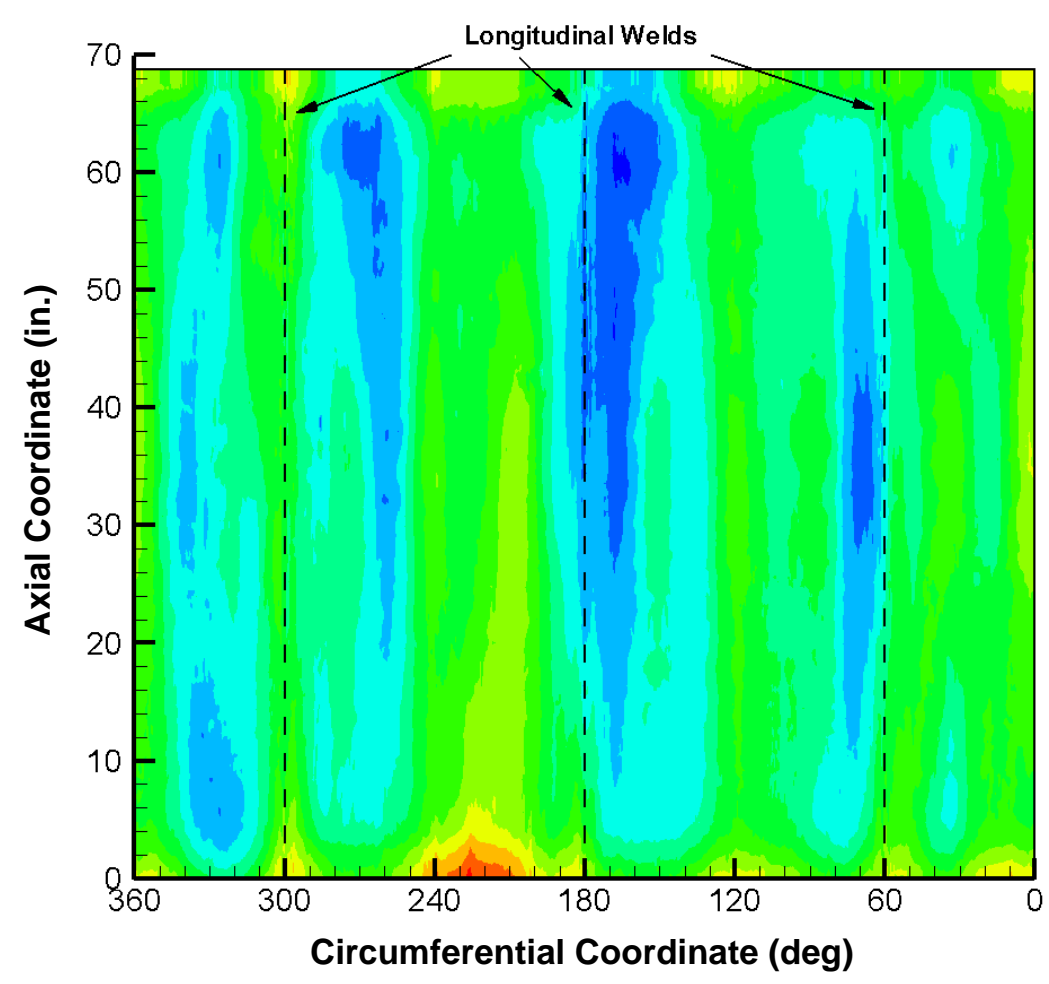

Figure 14. Measured geometric imperfection for TA01 (blue and red colored contours indicate inward and outward radial imperfections and the dashed vertical lines correspond to weld land locations). 


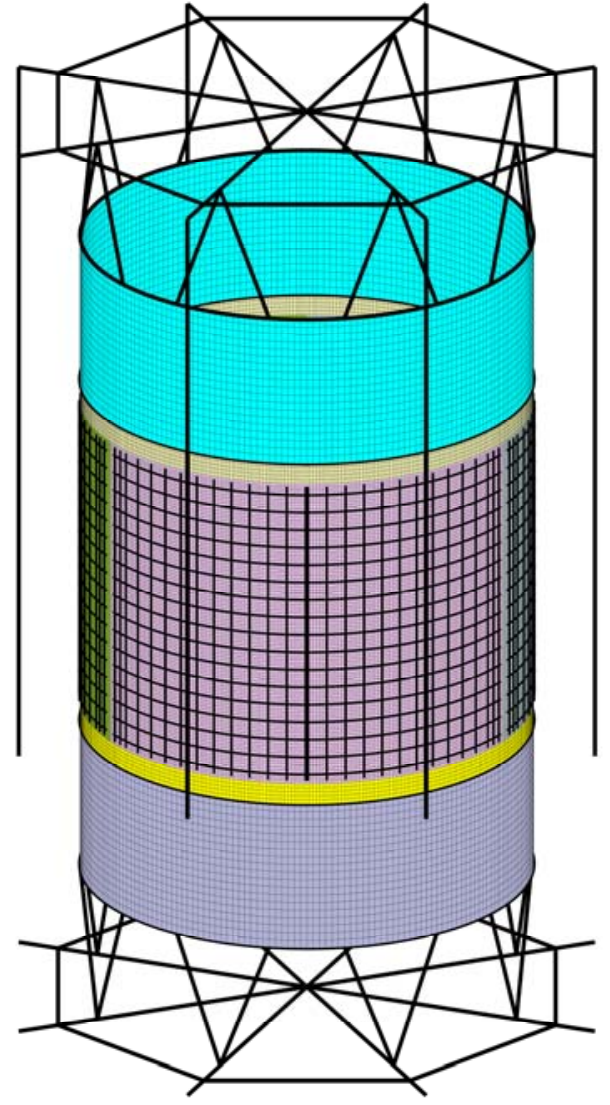

(a)

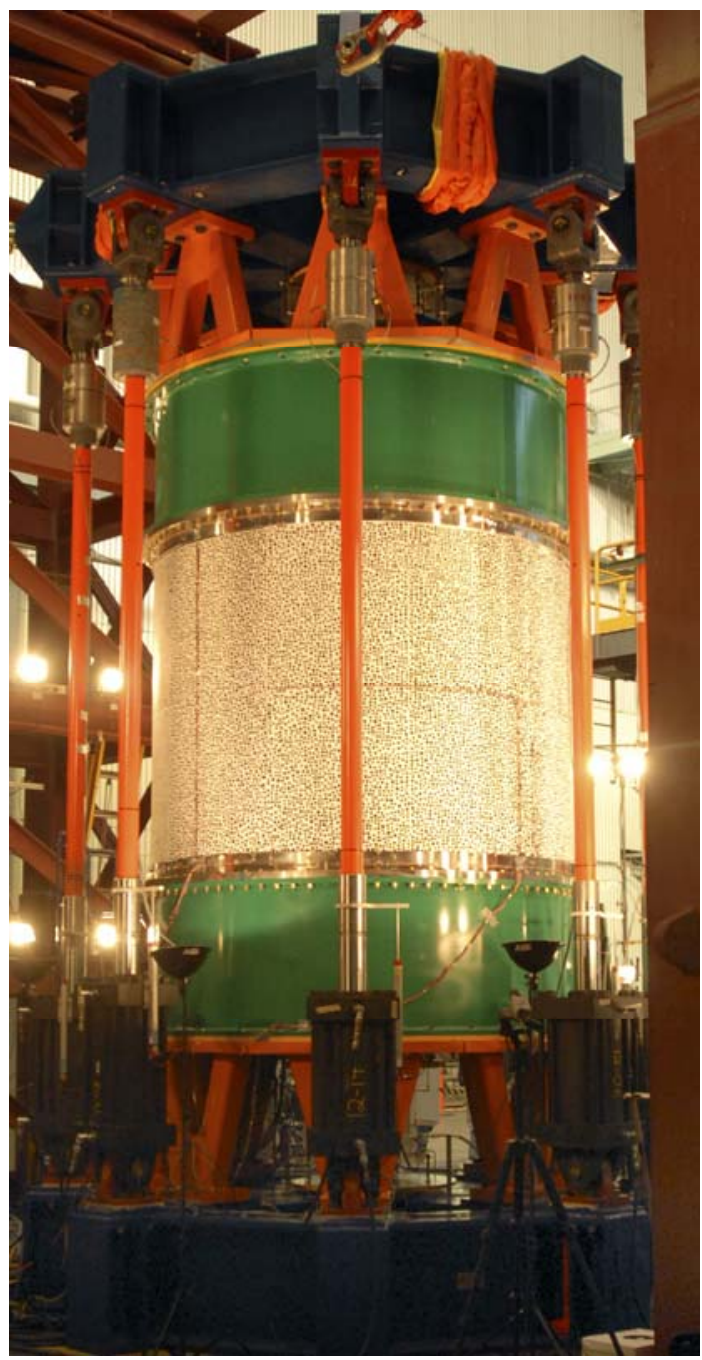

(b)

Figure 15. Typical finite-element mesh of 8-ft-diameter buckling test (a) and SBKF test facility (b). 


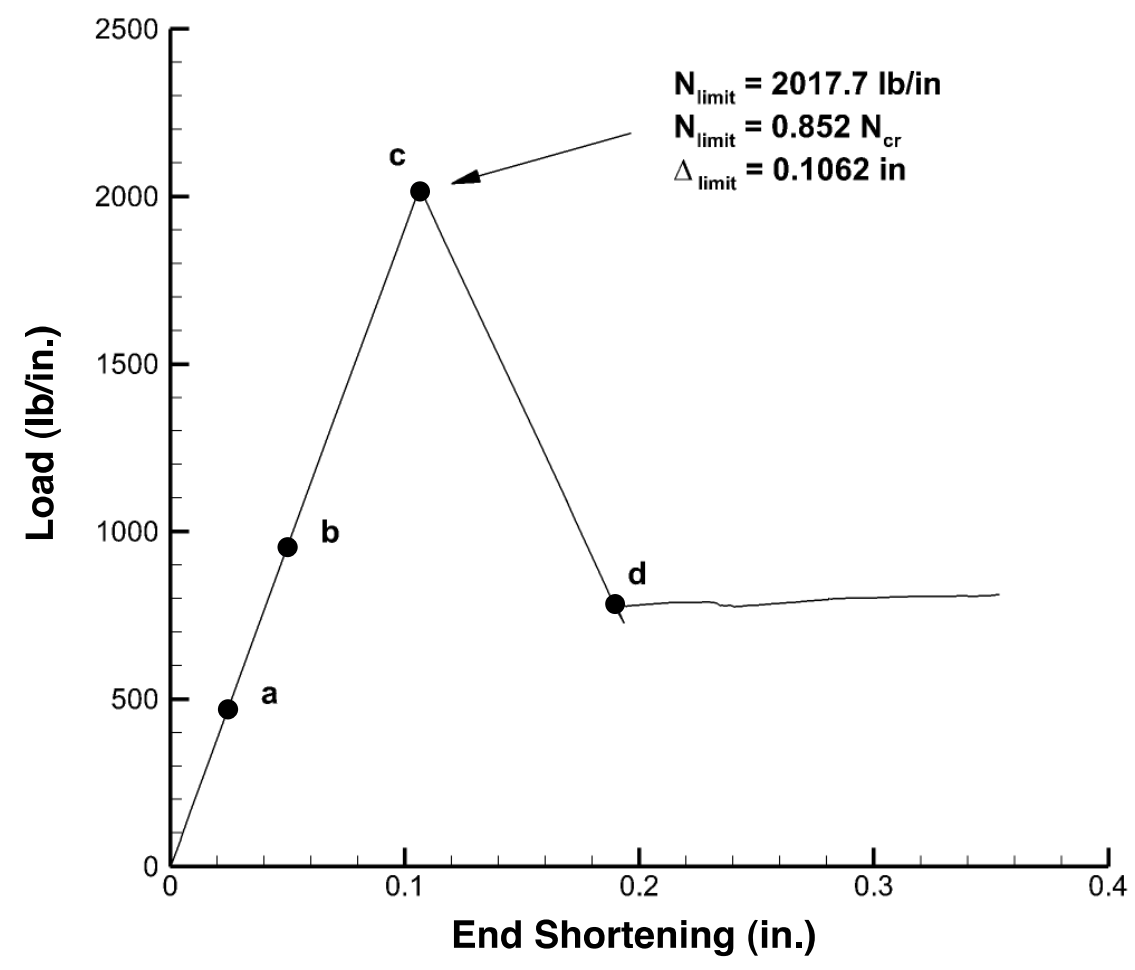

Figure 16. Predicted load-end-shortening response for TA01 subjected to uniform axial compression and including the as-measured geometric imperfection $\left(N_{c r}=2,368.2 \mathrm{lb} / \mathrm{in}.\right)$. 


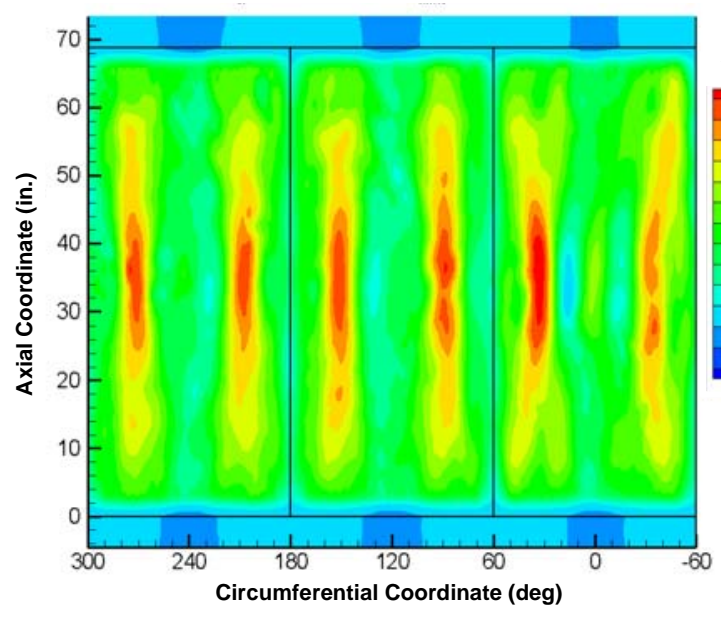

(a) $N_{x}=473.7 \mathrm{lb} / \mathrm{in}$.

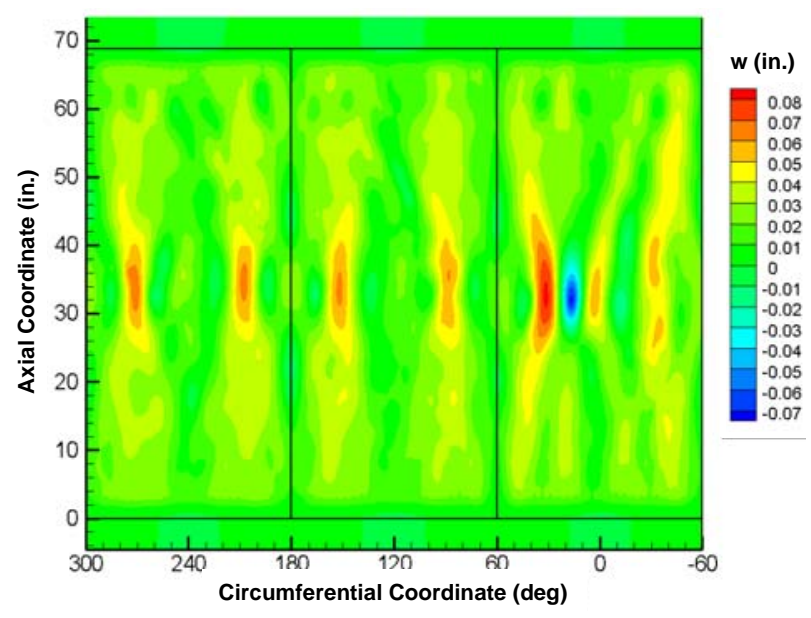

(c) Limit load, $N_{x}=2,018 \mathrm{lb} / \mathrm{in}$.

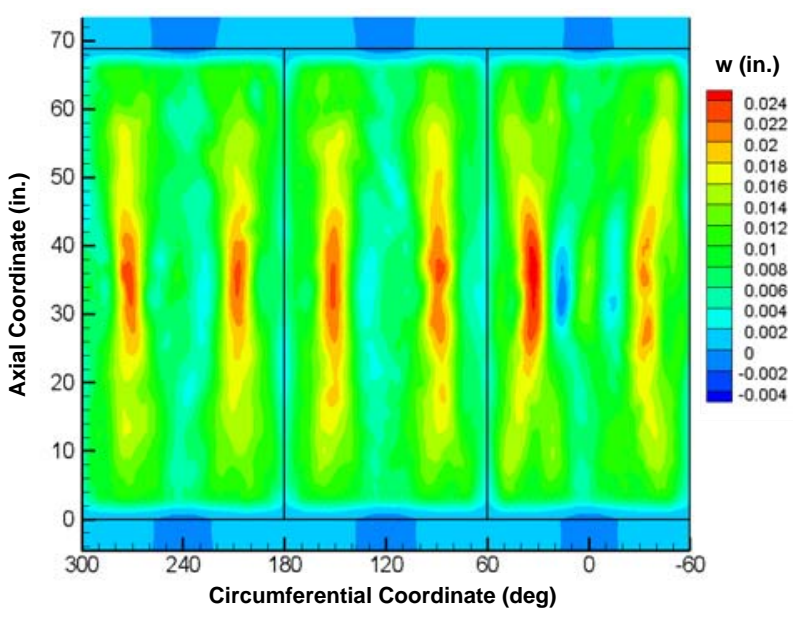

(b) $N_{x}=947.4 \mathrm{lb} / \mathrm{in}$.

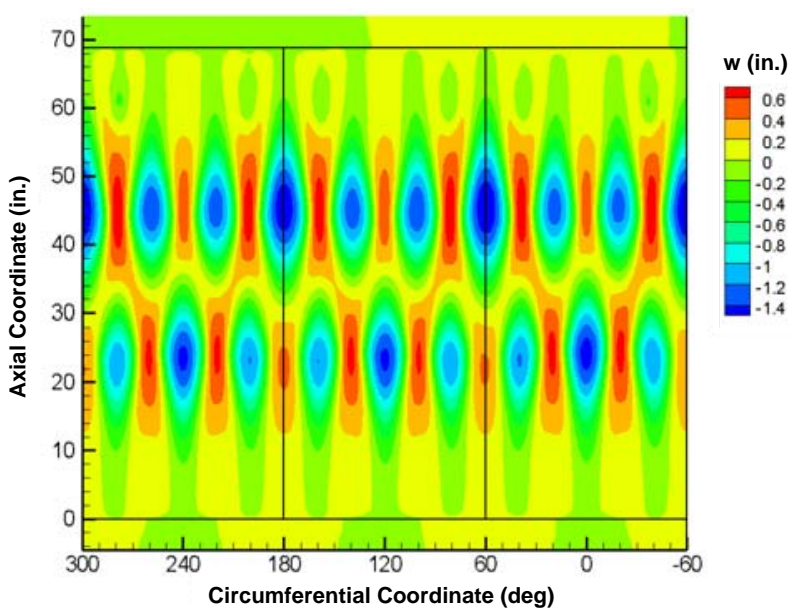

(d) Post-buckling, $N_{x}=1,800 \mathrm{lb} / \mathrm{in}$.

Figure 17. Predicted radial deformation response for TA01 subjected to uniform axial compression and including as-measured geometric imperfection. 


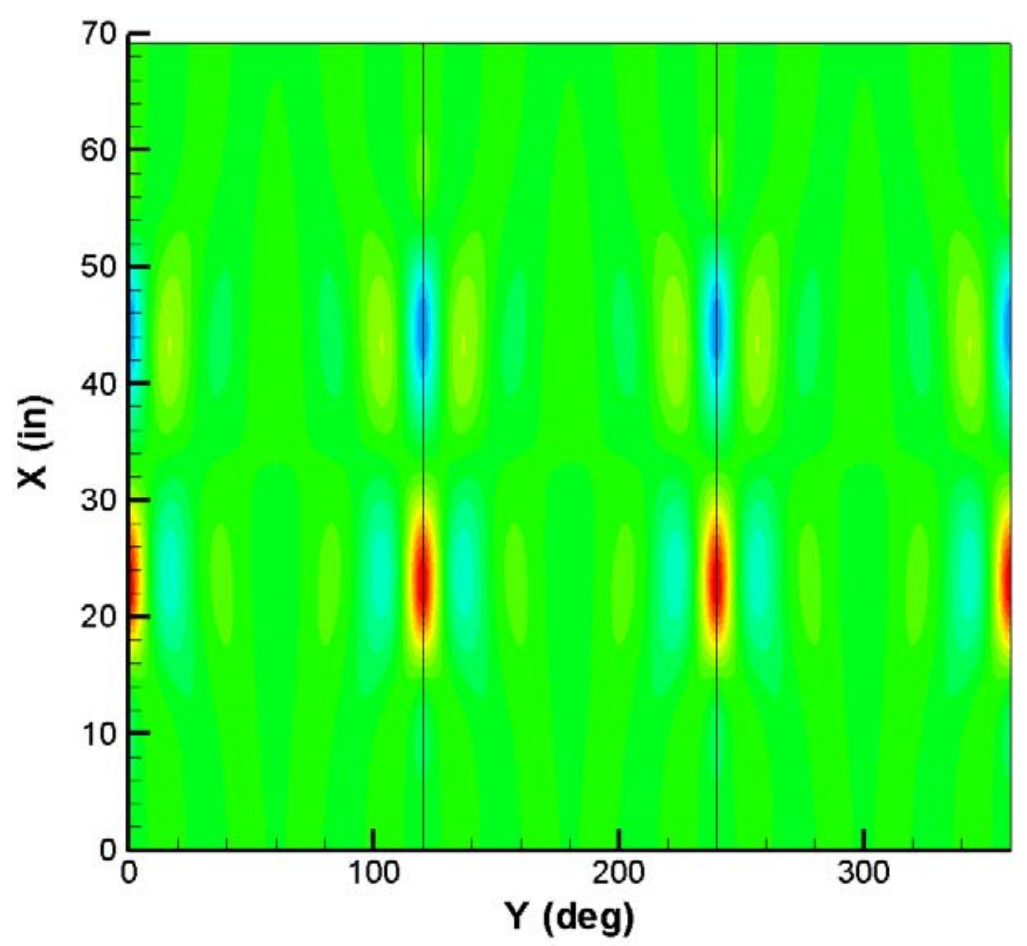

(a) global detailed model

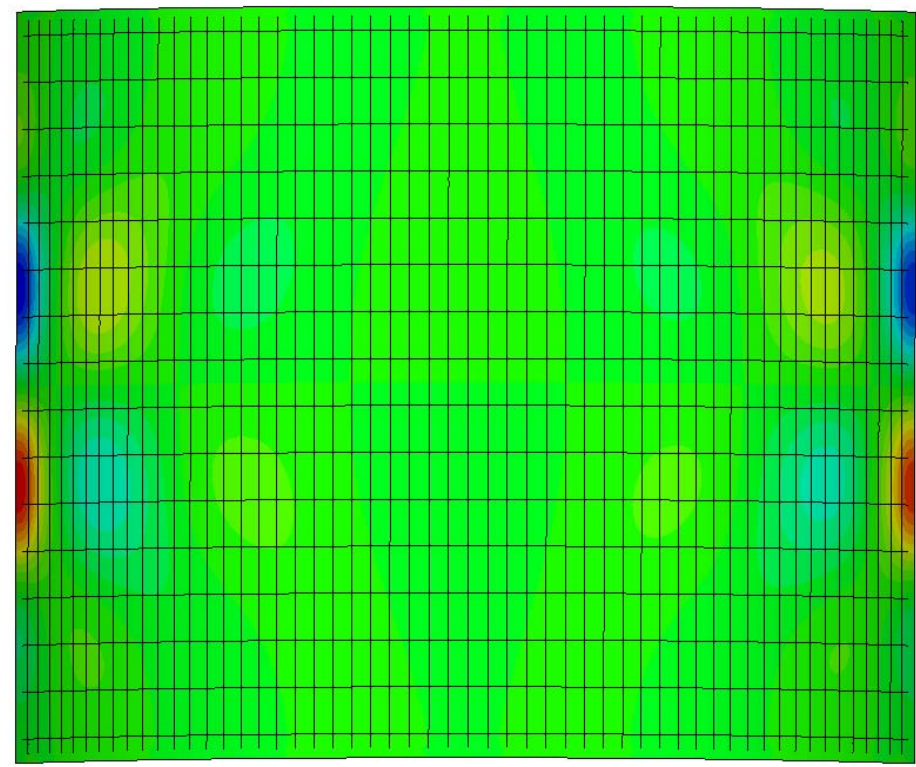

(b) local detailed model of a single curve panel section between weld lands with stiffeners modeled with shell elements

Figure 18. Linear buckling mode shapes for TA03 from global and local models.

American Institute of Aeronautics and Astronautics 


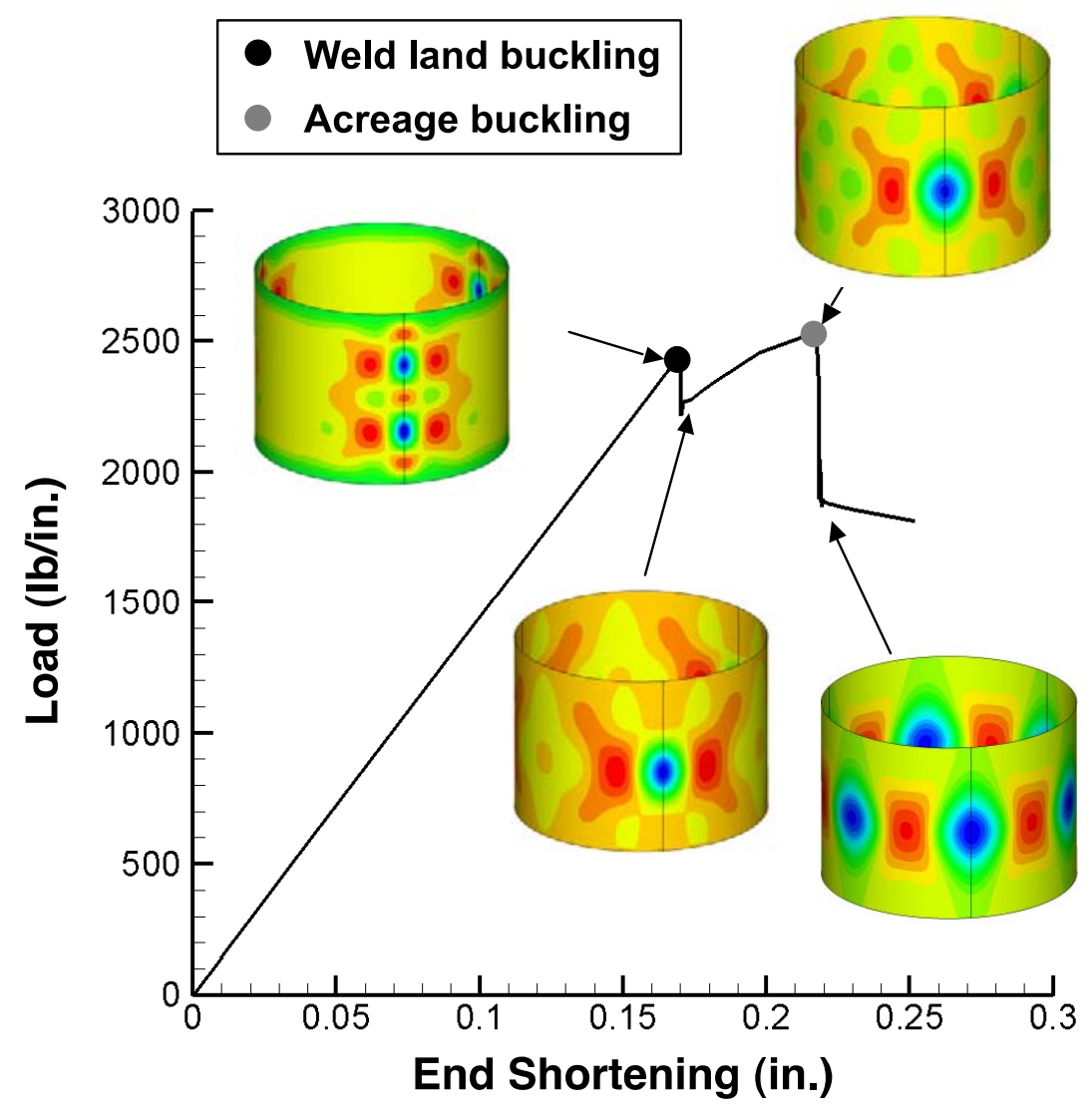

Figure 19. Predicted load-end-shortening response and selected radial displacement contours of geometrically perfect TA03. 


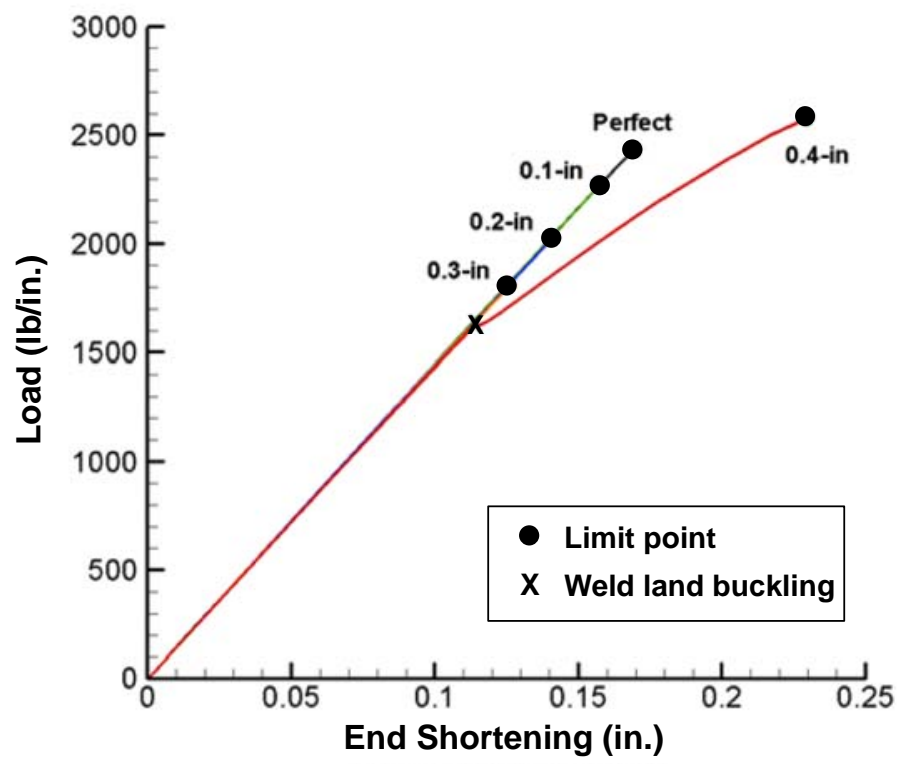

Figure 20. Predicted load-end-shortening response of TA03 with selected weld land imperfection amplitudes. 


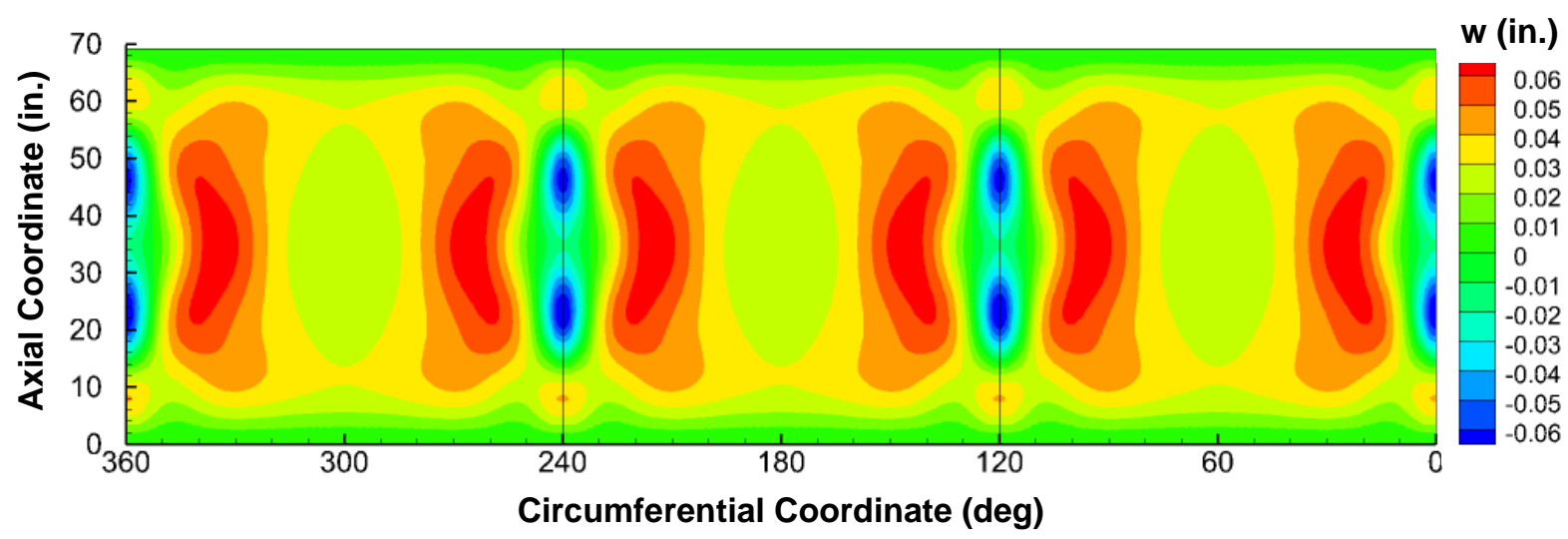

(a) Imperfection amplitude $A=0.1$ in.

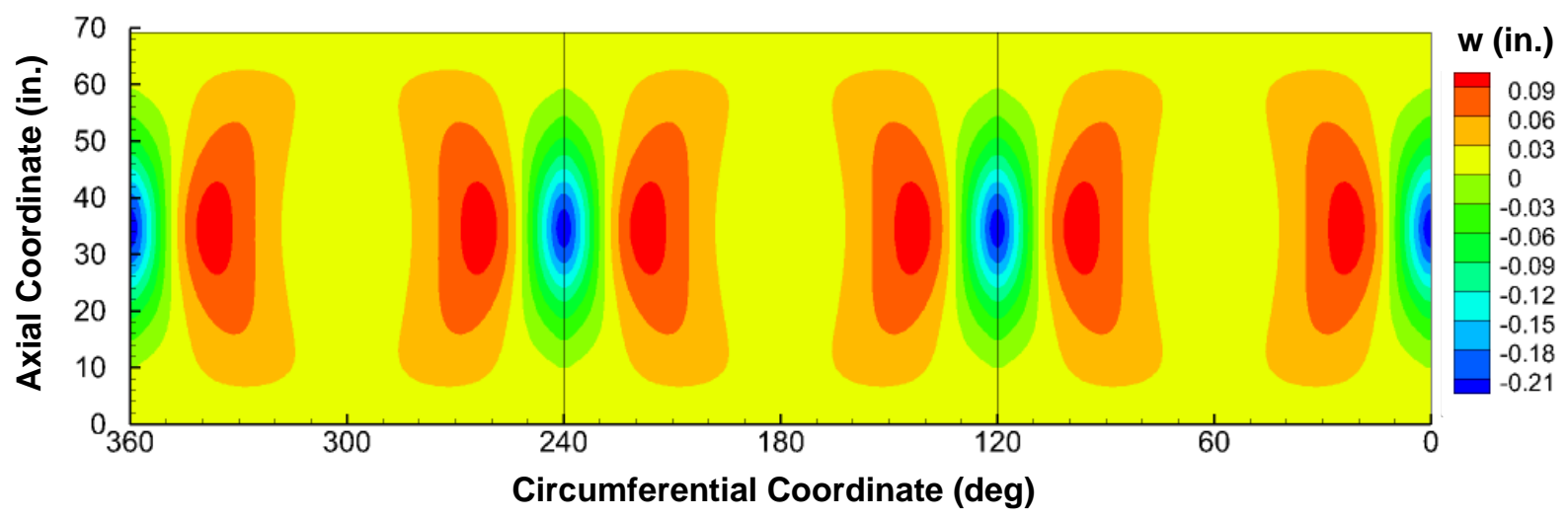

(b) Imperfection amplitude $A=0.3$ in.

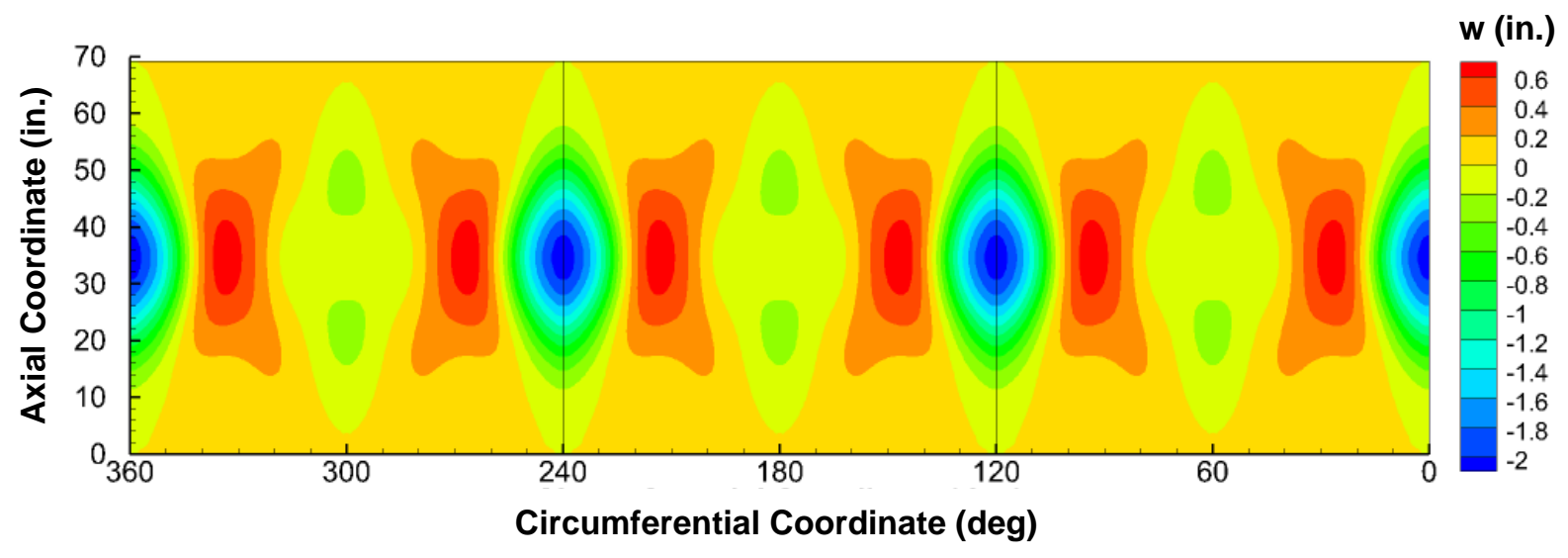

(3) Imperfection amplitude $A=0.4$ in.

Figure 21. Predicted radial displacement contours at the limit load for TA03 with selected weld land imperfection amplitudes (blue and red red contours correspond to inward and outward radial displacements, respectively, and vertical lines represent the locations of longitudinal weld lands). 


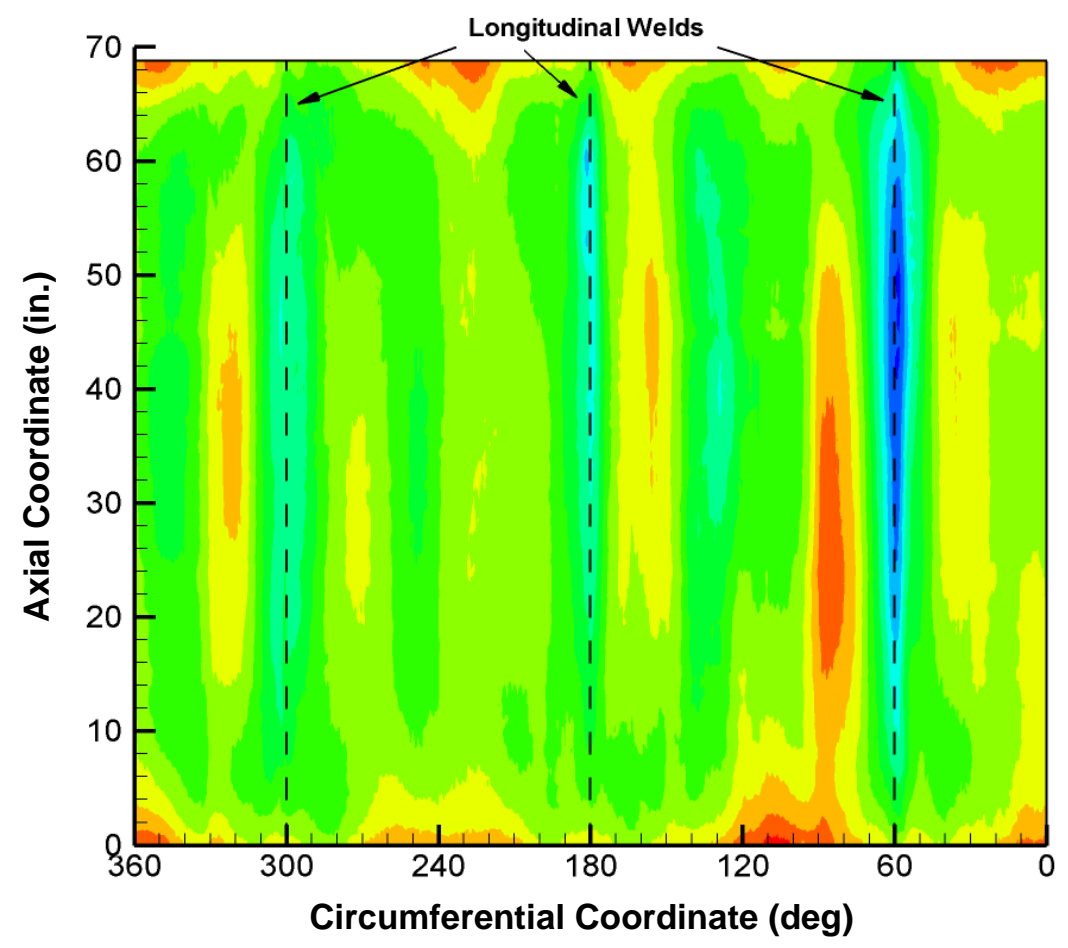

Figure 22. Measured geometric imperfection for TA03 (blue and red contours correspond to inward and outward radial imperfections. 


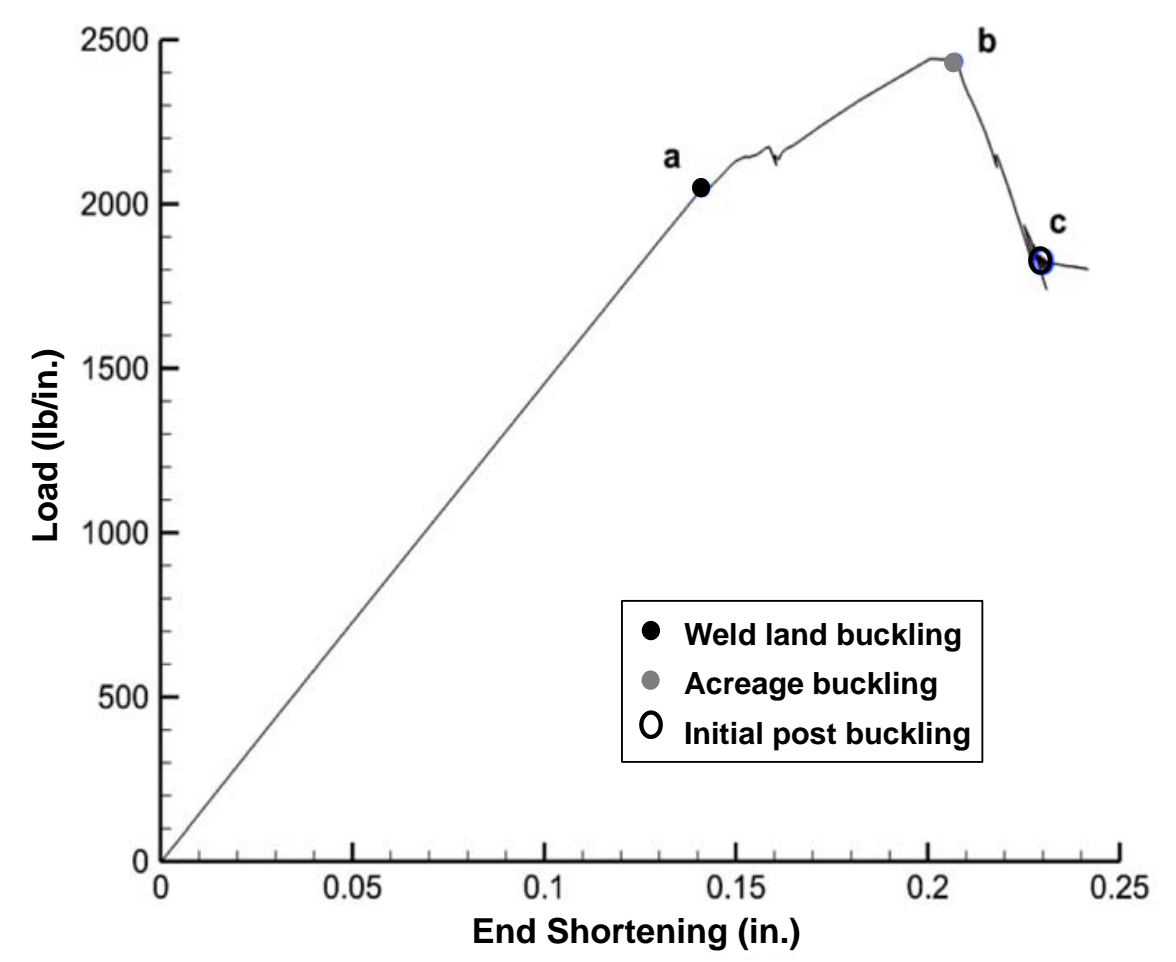

Figure 23. Predicted load-end-shortening response for TA03 subjected to uniform axial loading and including as-measured geometric imperfection. 


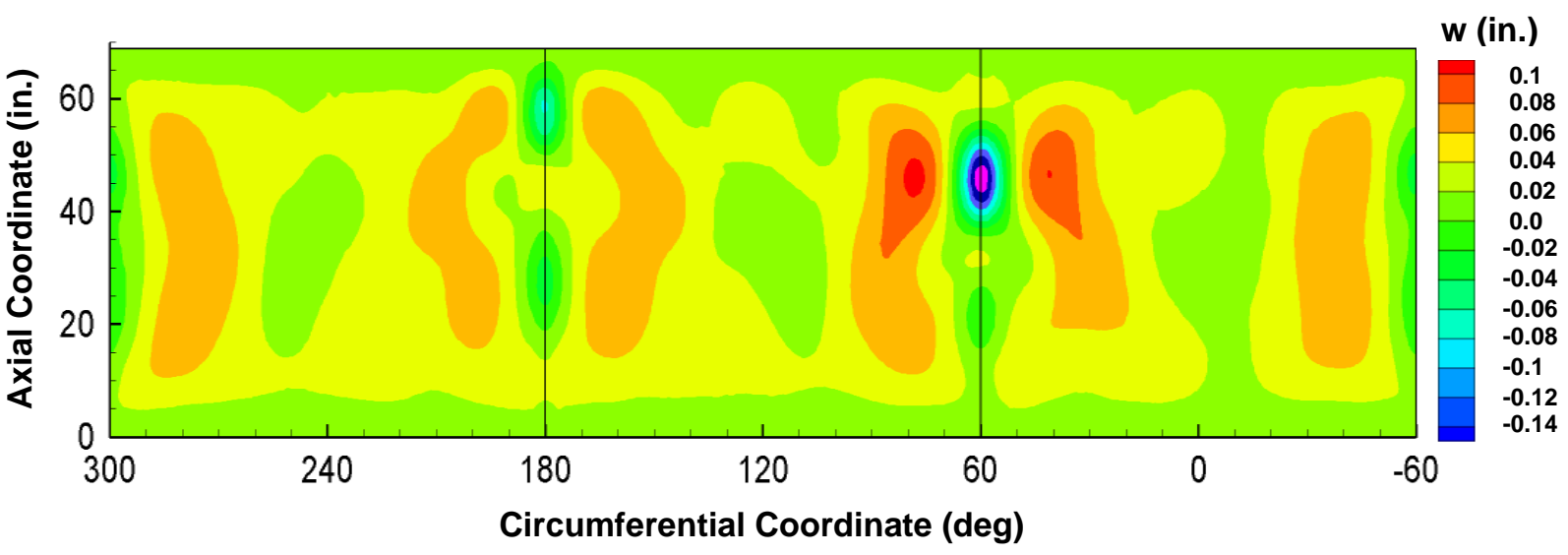

(a) Initial weld land buckling

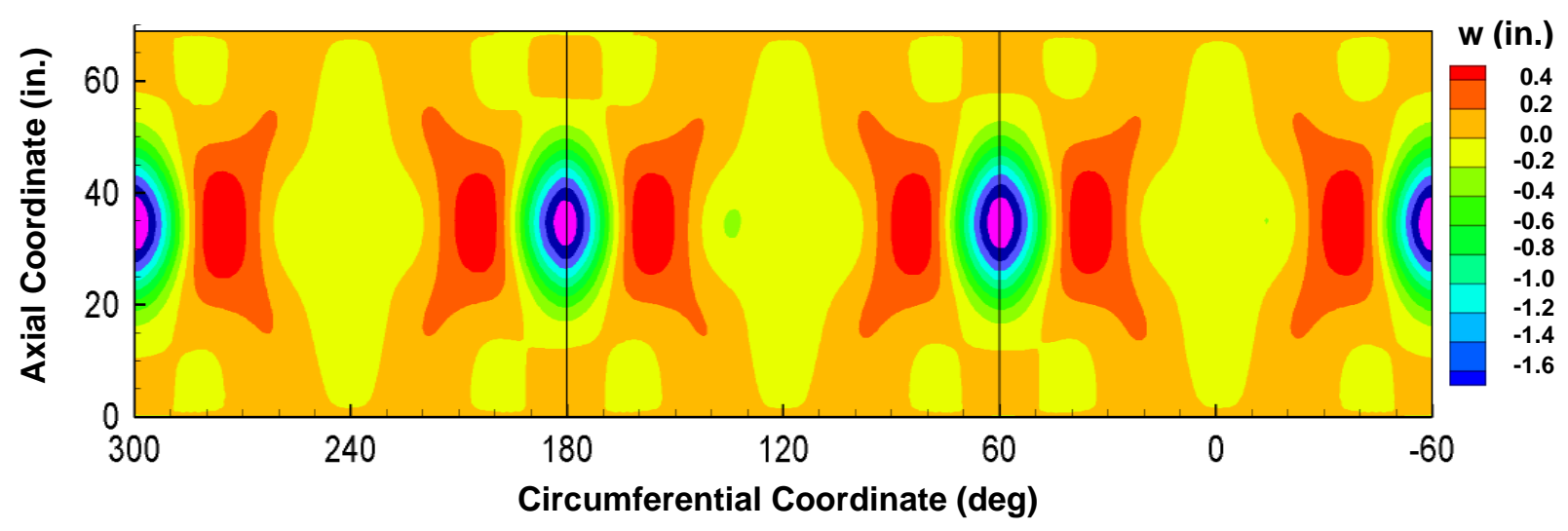

(b) Limit point

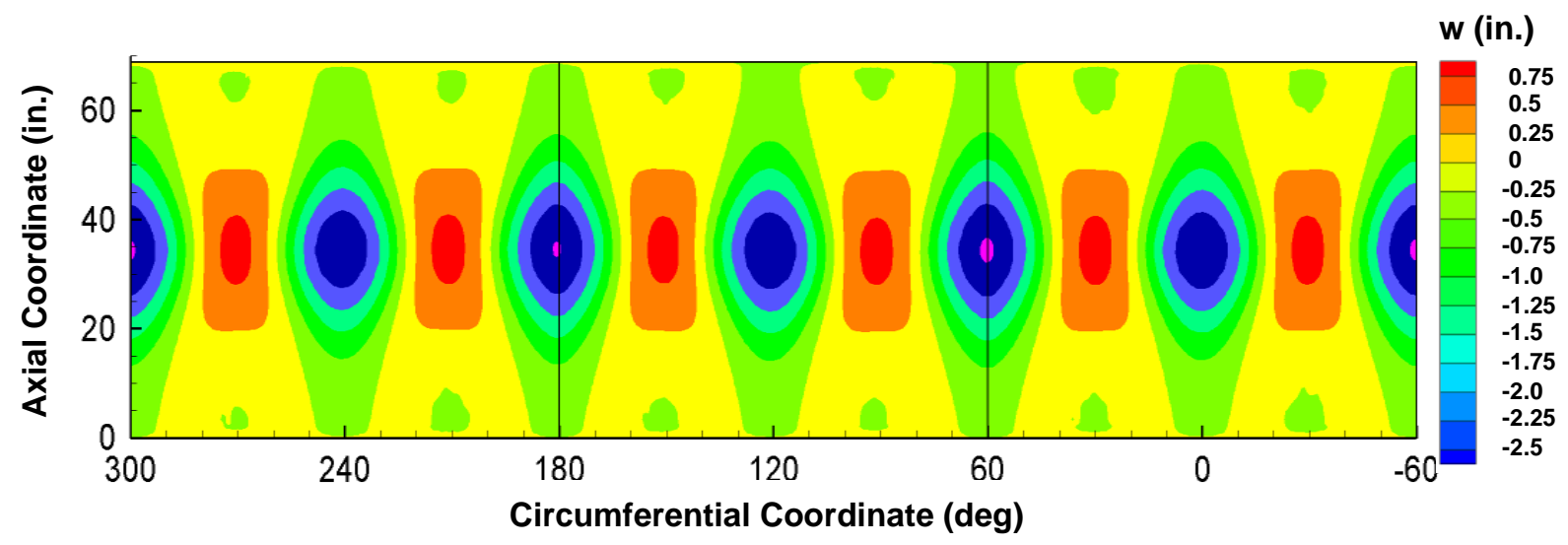

(c) Acreage buckling

Figure 24. Predicted radial displacement contours for TA03 at selected load levels. 


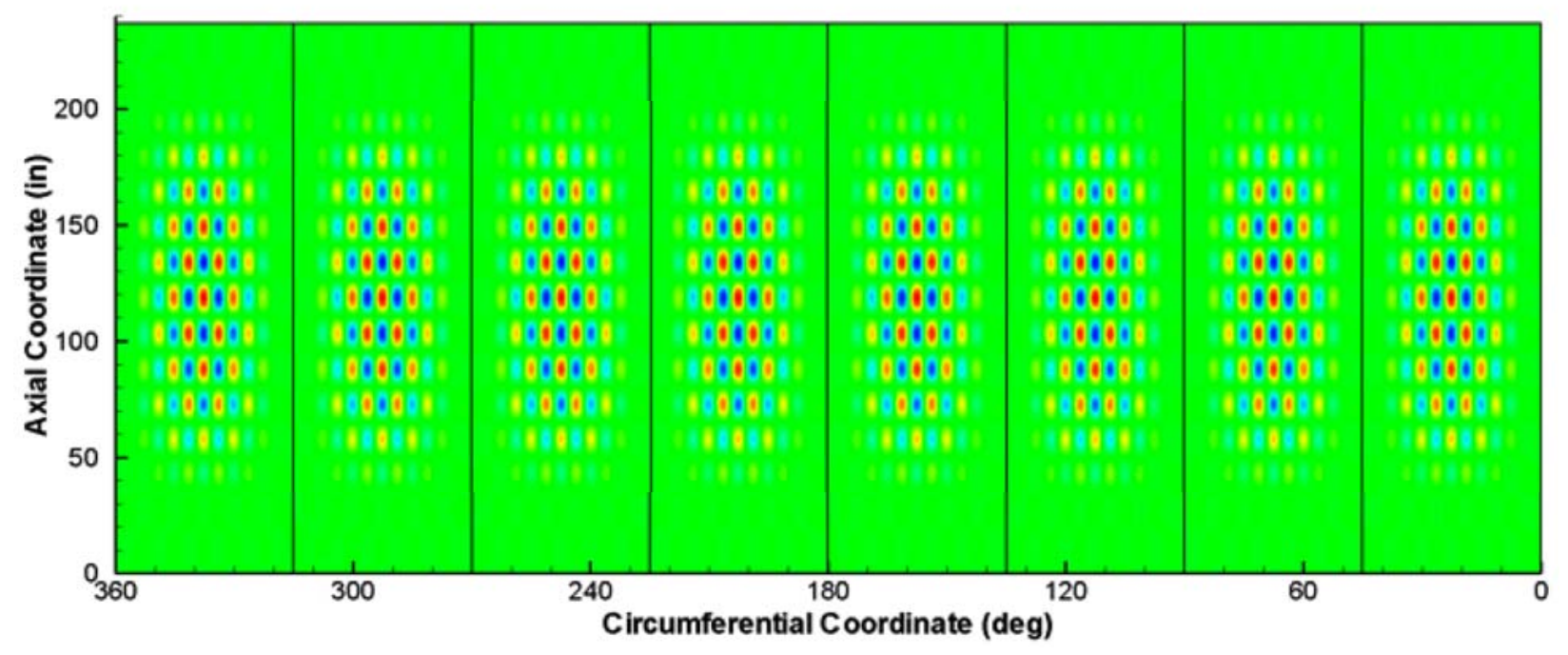

Figure 25. Linear bifurcation buckling mode shape from a geometrically perfect detailed model of ETTA1. 


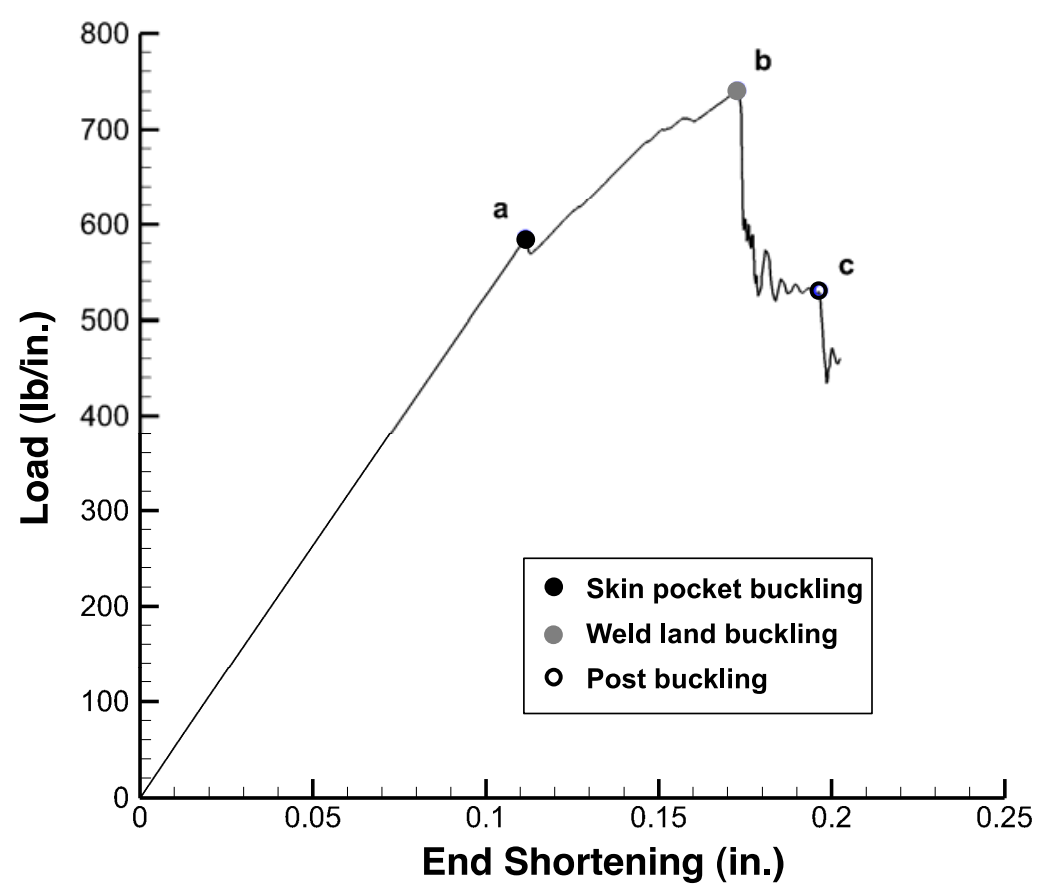

Figure 26. Predicted load-end-shortening response for geometrically perfect ETTA1. 


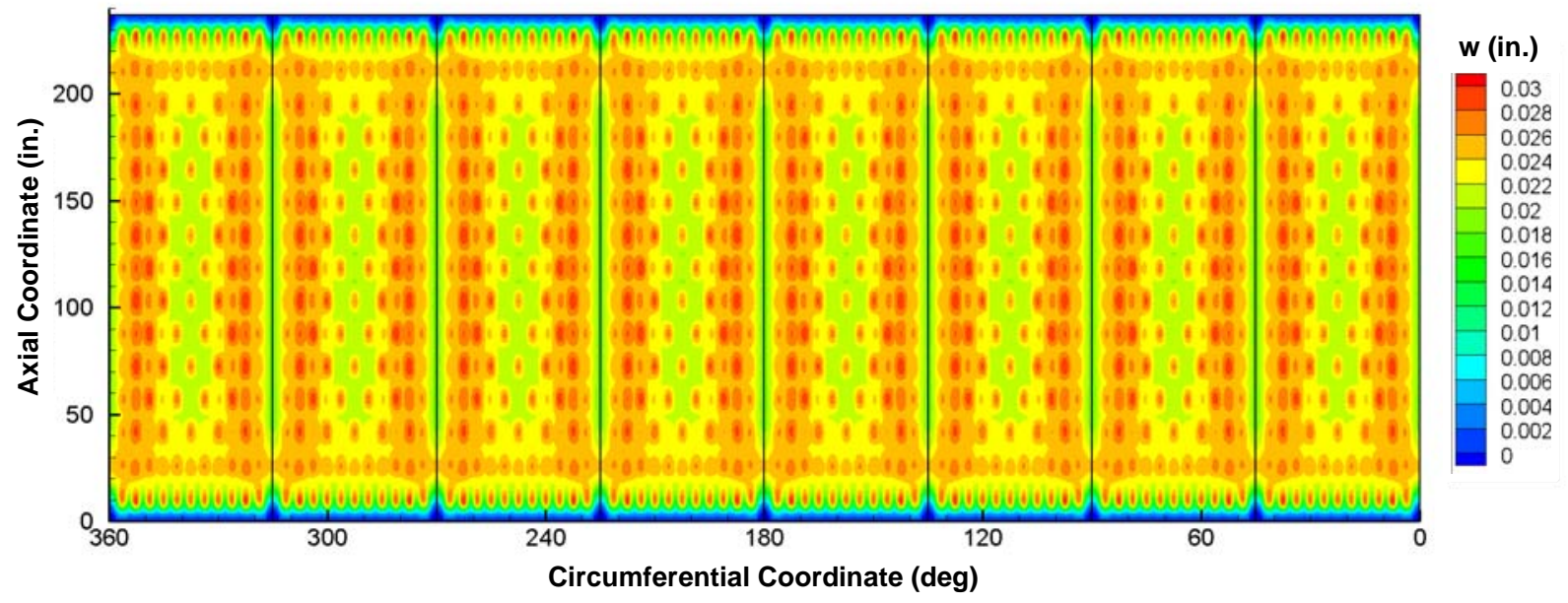

(a) Skin pocket buckling

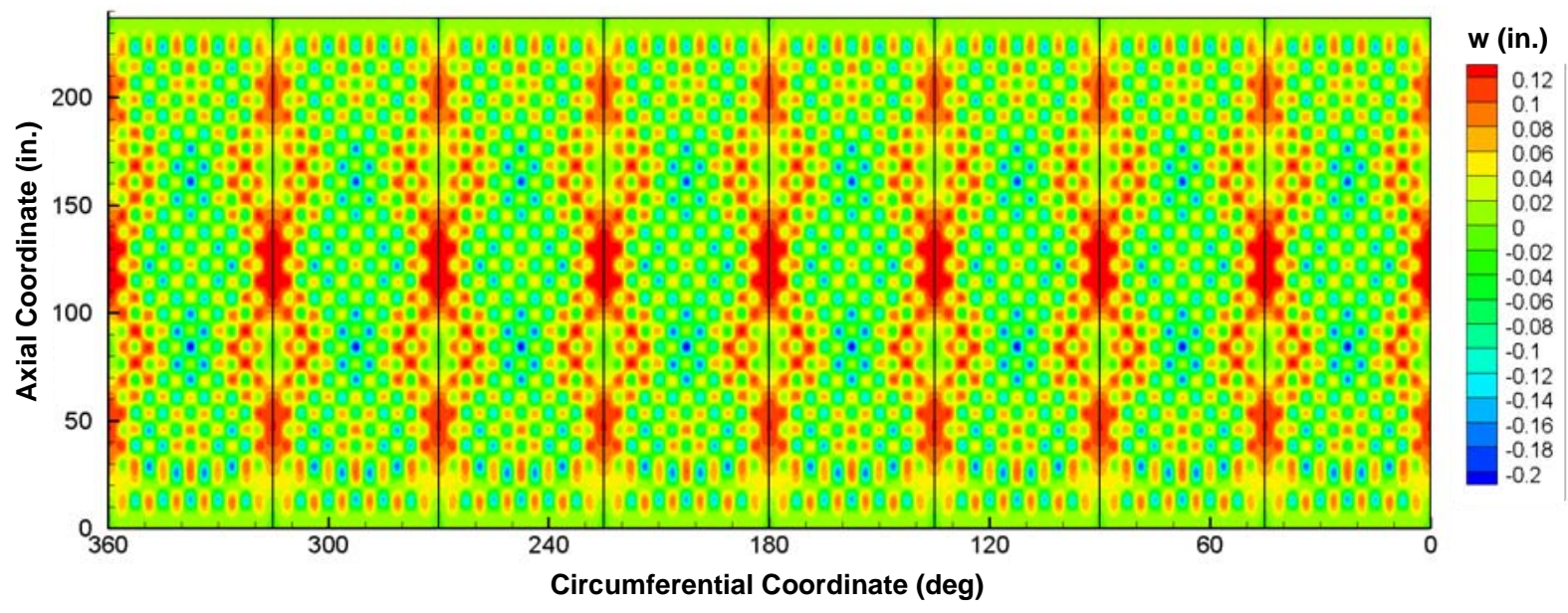

(b) Limit load and incipient weld land buckling

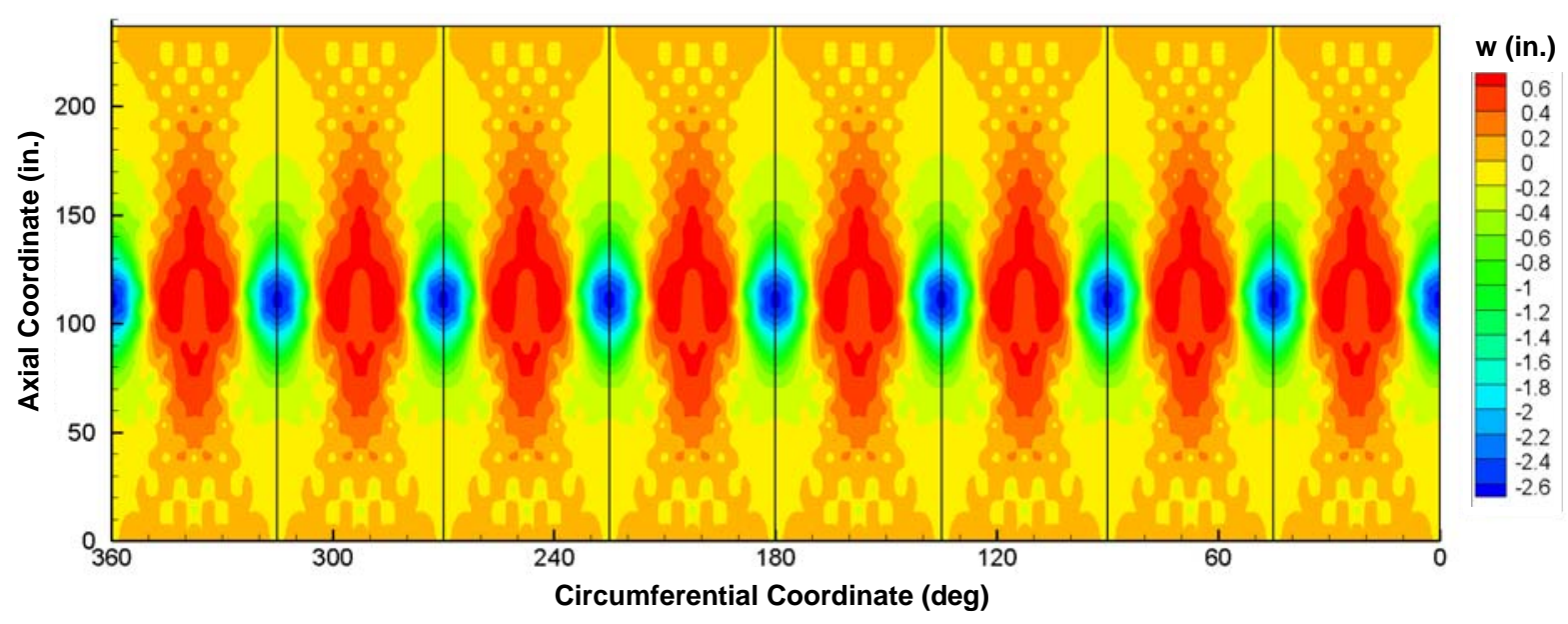

(c) Post weld land buckling

Figure 27 Predicted radial displacement contours for geometrically perfect ETTA1.

American Institute of Aeronautics and Astronautics 


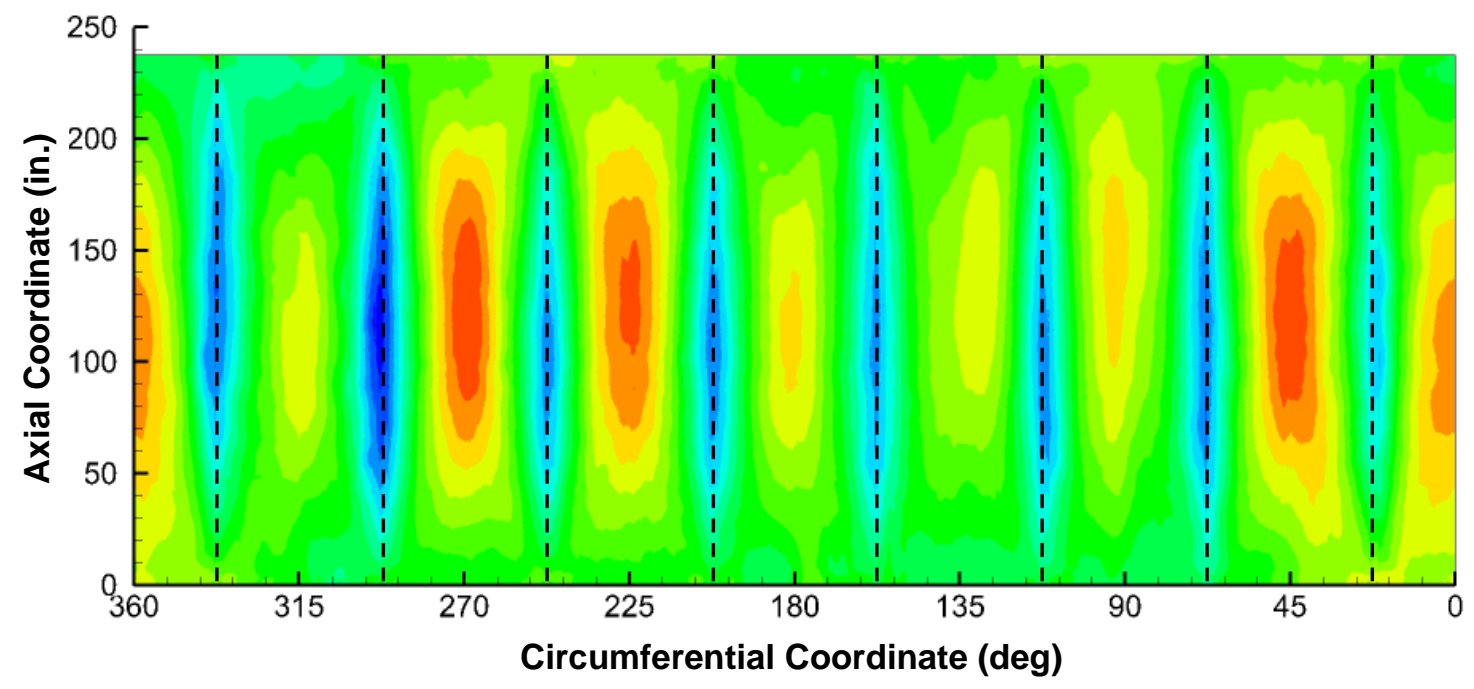

Figure 28. Measured geometric imperfection for ETTA1 (blue and red colored contours correspond to inward and outward radial deformations, respectively, and the vertical dashed lines indicate the location of longitudinal weld lands). 


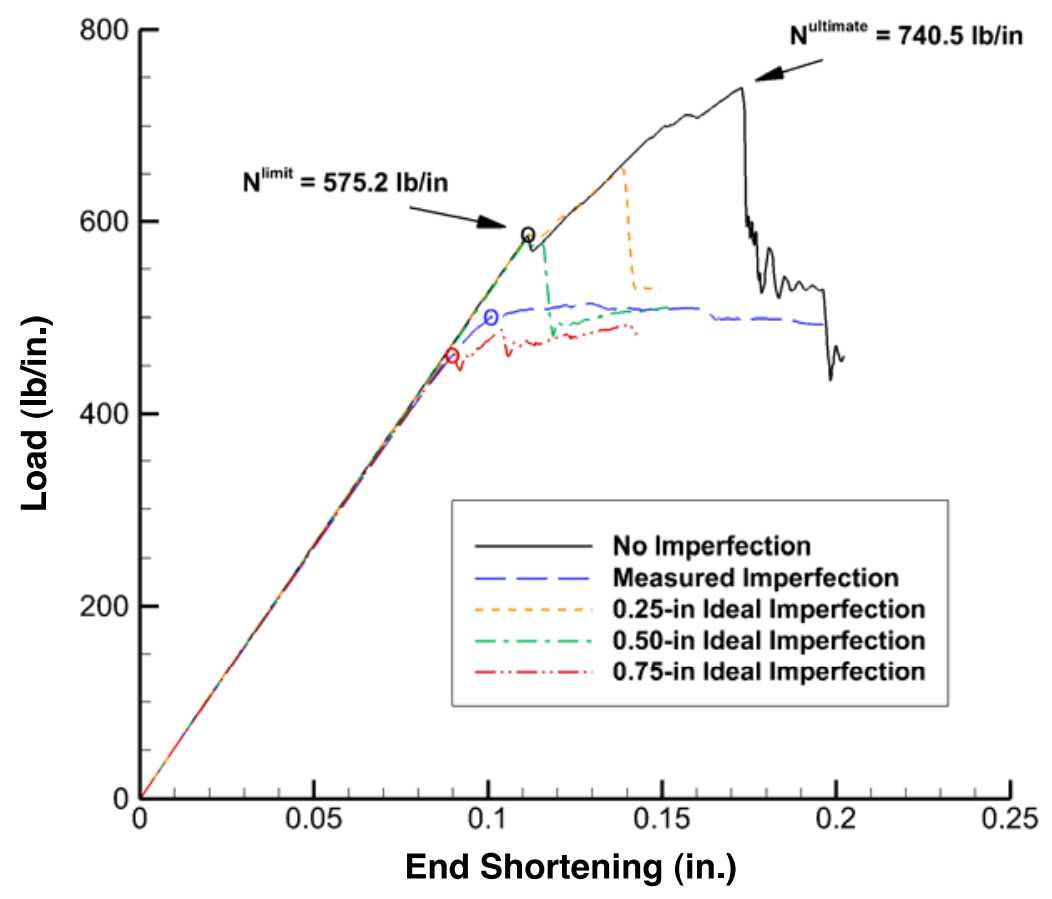

Figure 29. Predicted load-end-shortening response for ETTA1 with selected geometric imperfections. 


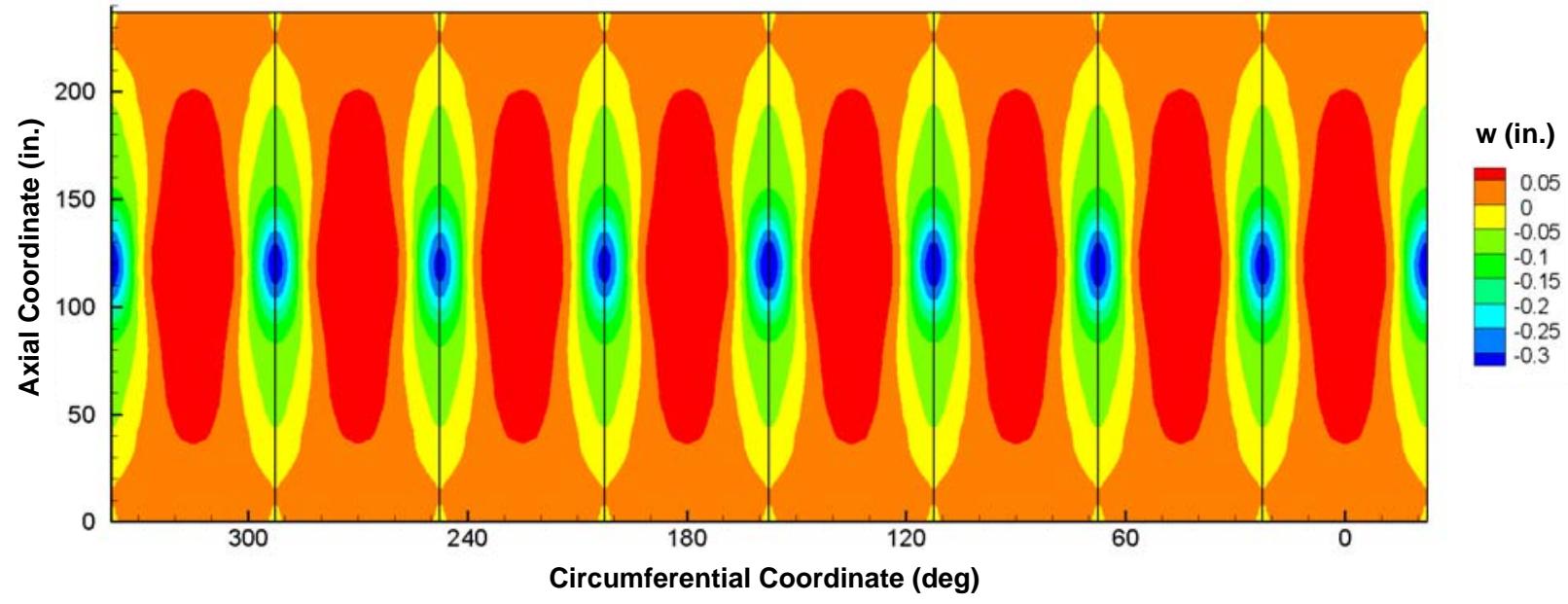

Figure 30. Predicted radial displacement contours for ETTA1 with a weld land geometric imperfection amplitude $A=0.75$ in. (blue and red contours are inward and outward radial displacements respectively, and black vertical lines indicate longitudinal weld land locations). lose 


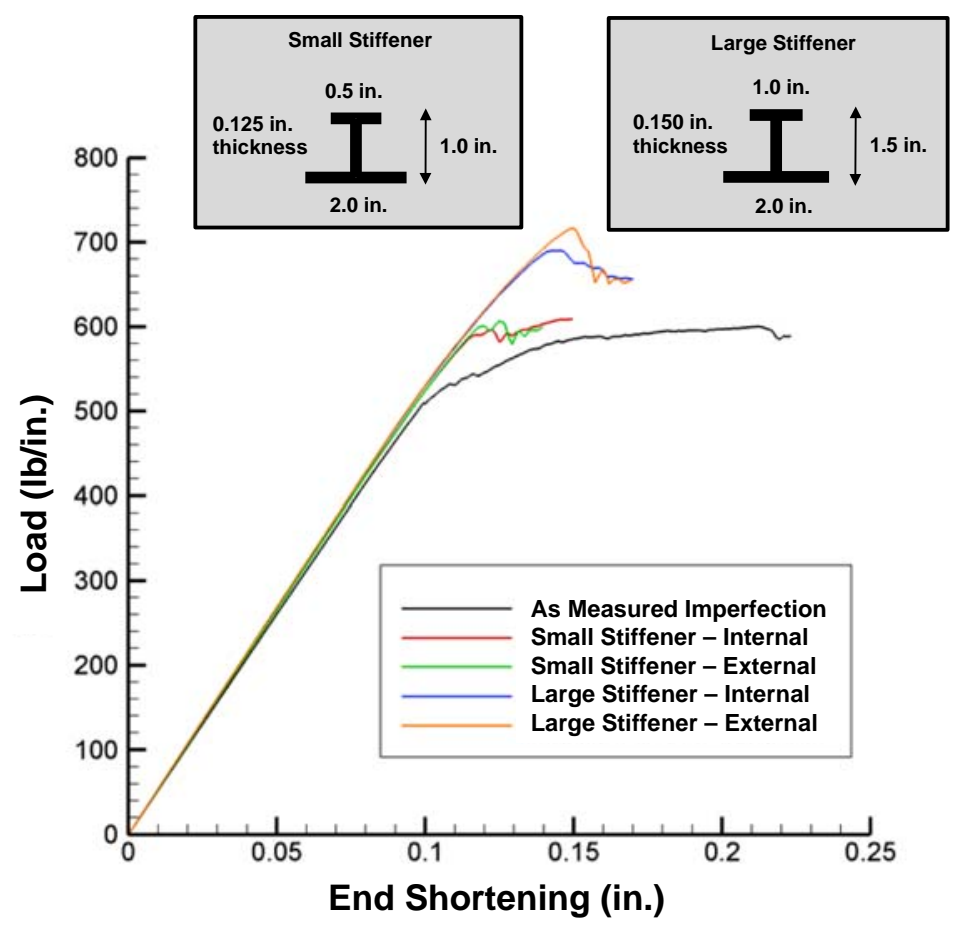

Figure 31. Predicted load-end-shortening response of imperfect ETTA1 with different weld land stiffening options and subjected to axial compression.

American Institute of Aeronautics and Astronautics 


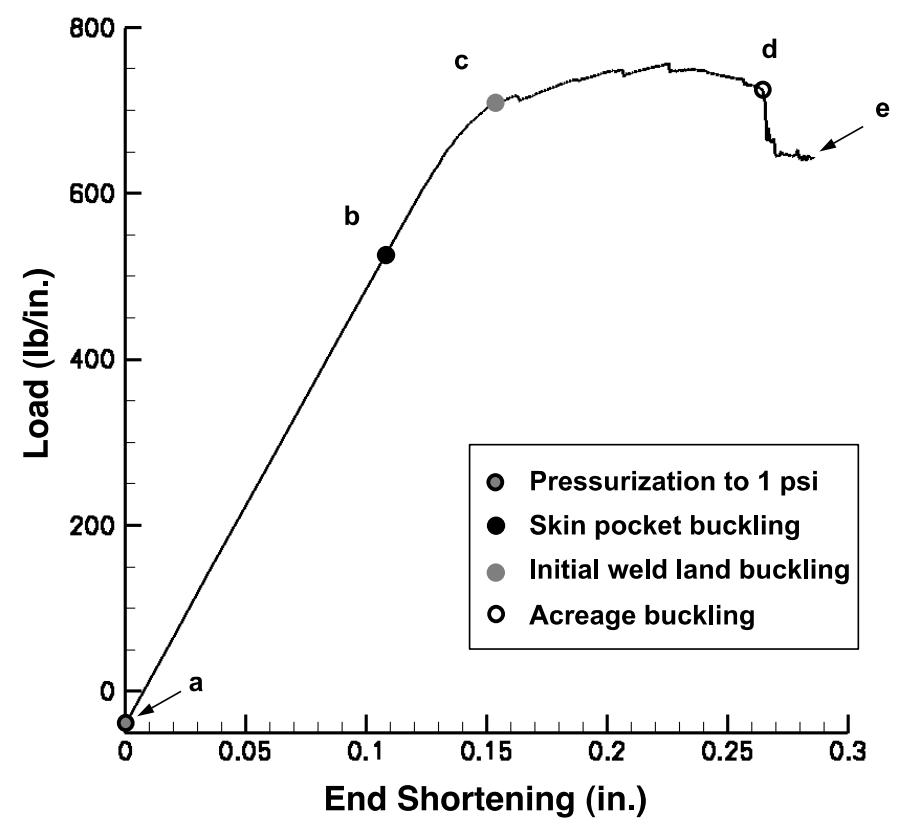

Figure 32. Predicted load-end-shortening response of imperfect ETTA1 subjected to 1 psi internal pressure and axial compression (labels a-e correspond to predicted displacement contours shown in Fig. 33). 


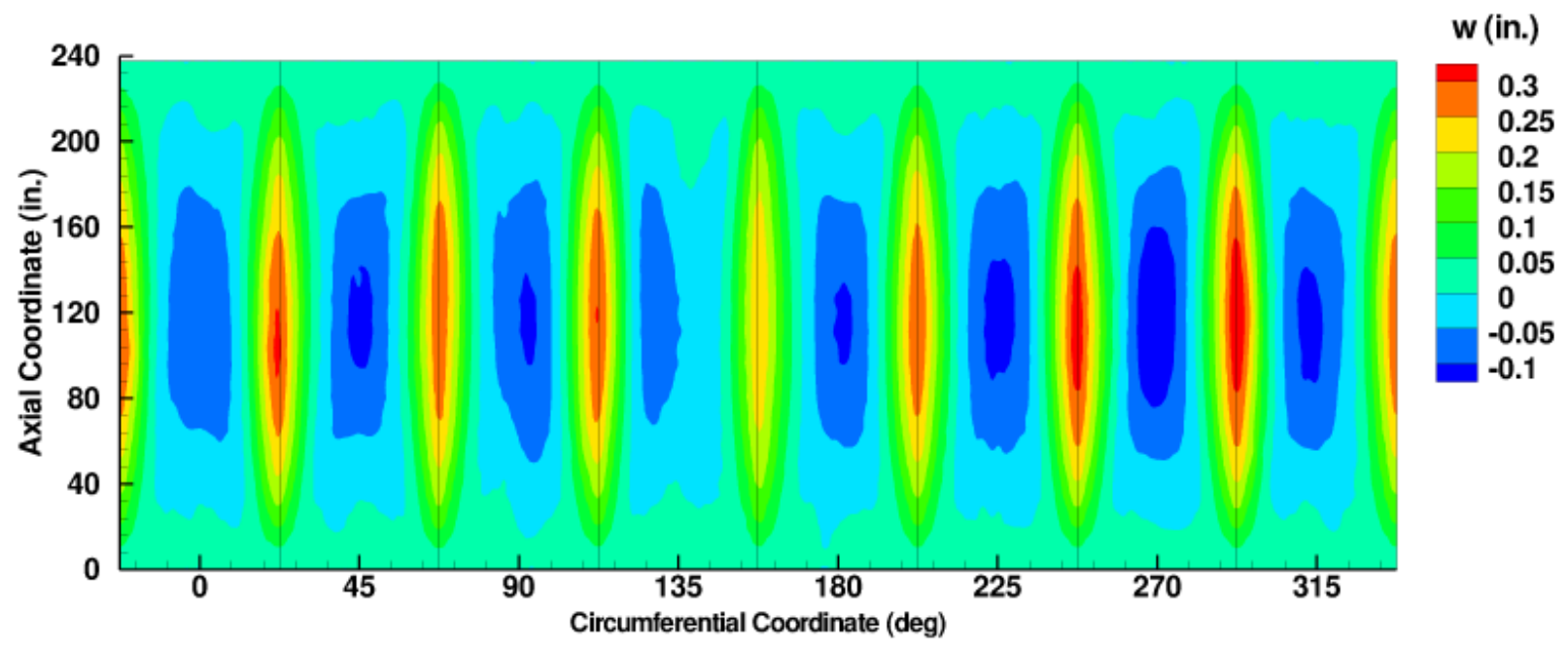

(a) 1 psi loading only.

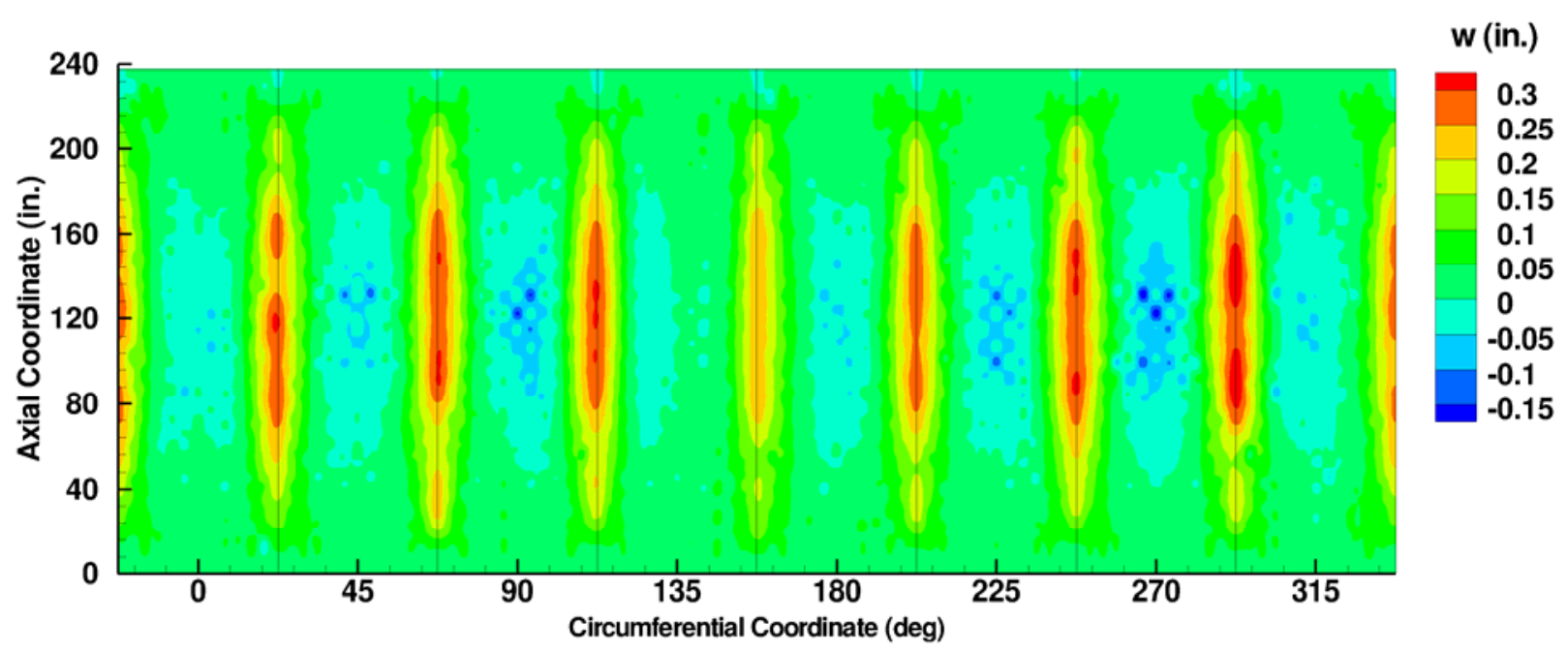

(b) Skin pocket buckling.

Figure 33. Predicted radial displacement contours for imperfect ETTA1 subjected to 1 psi internal pressure and axial compression (blue and red colored contours correspond to inward and outward radial deformations, respectively, and vertical black lines correspond to longitudinal weld land locations). 


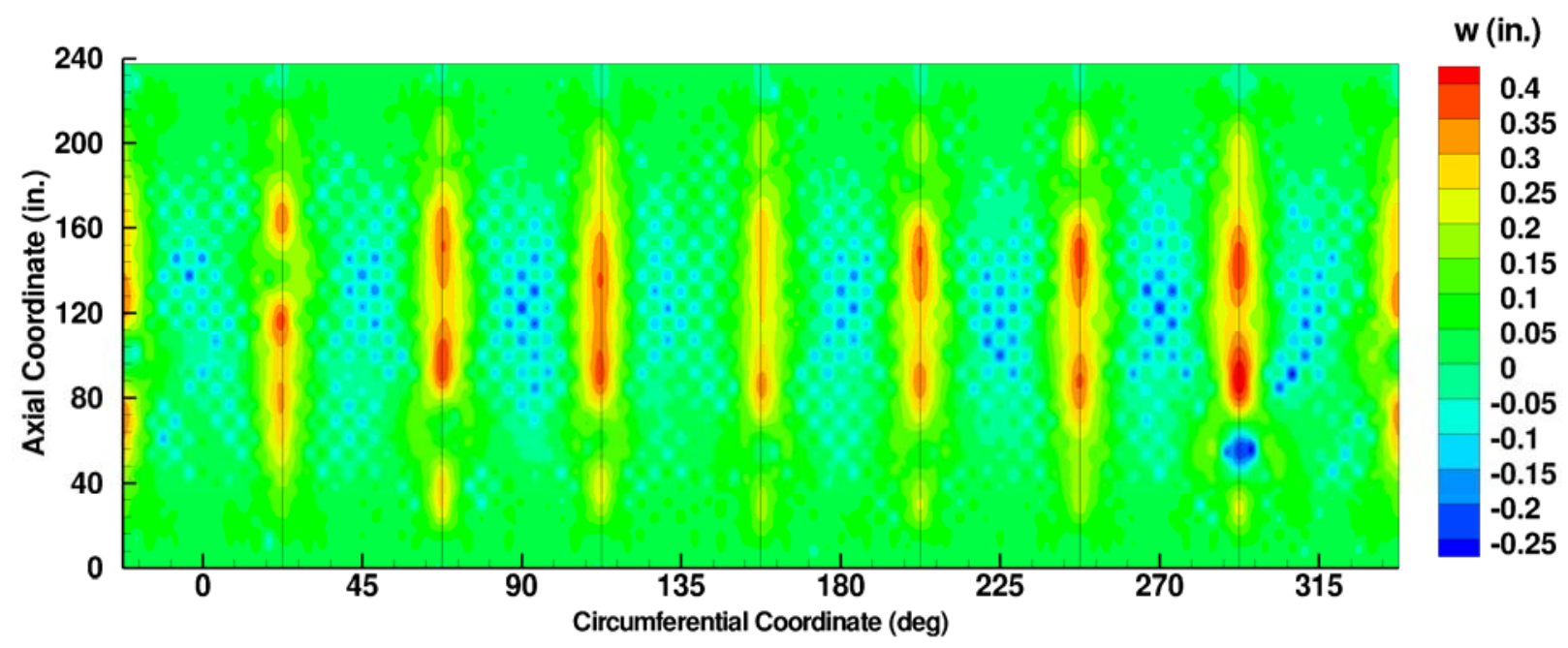

(c) Initial weld land buckling.

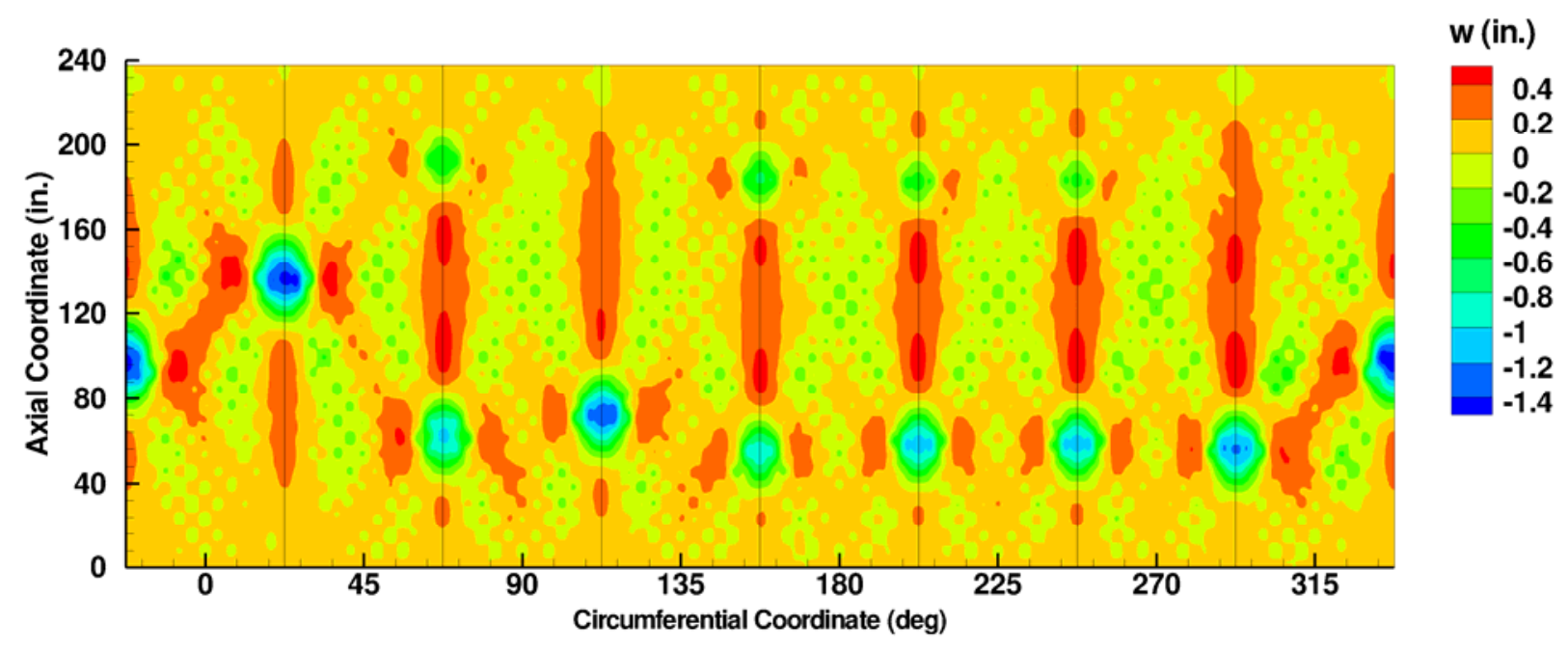

(d) Incipient global buckling.

Figure 33 (continued). Predicted radial displacement contours for imperfect ETTA1 subjected to 1 psi internal pressure and axial compression (blue and red colored contours correspond to inward and outward radial deformations, respectively, and vertical black lines correspond to longitudinal weld land locations). 


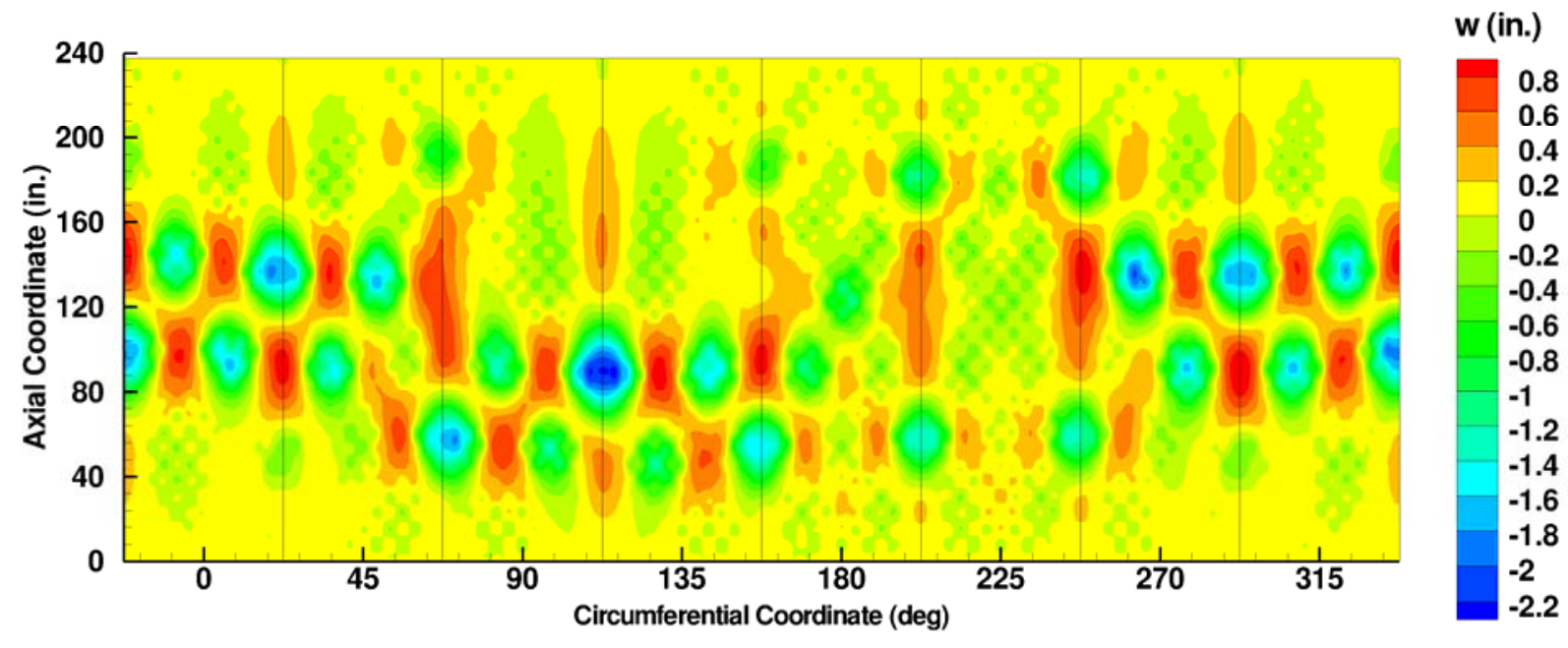

(e) Post global (acreage) buckling.

Figure 33 (concluded). Predicted radial displacement contours for imperfect ETTA1 subjected to 1 psi internal pressure and axial compression (blue and red colored contours correspond to inward and outward radial deformations, respectively, and vertical black lines correspond to longitudinal weld land locations). 